\title{
Manual de campo
}

para reconocimiento, monitoreo " y manejo de las enfermedades de la mora (Rulbus glaucus Benth.)

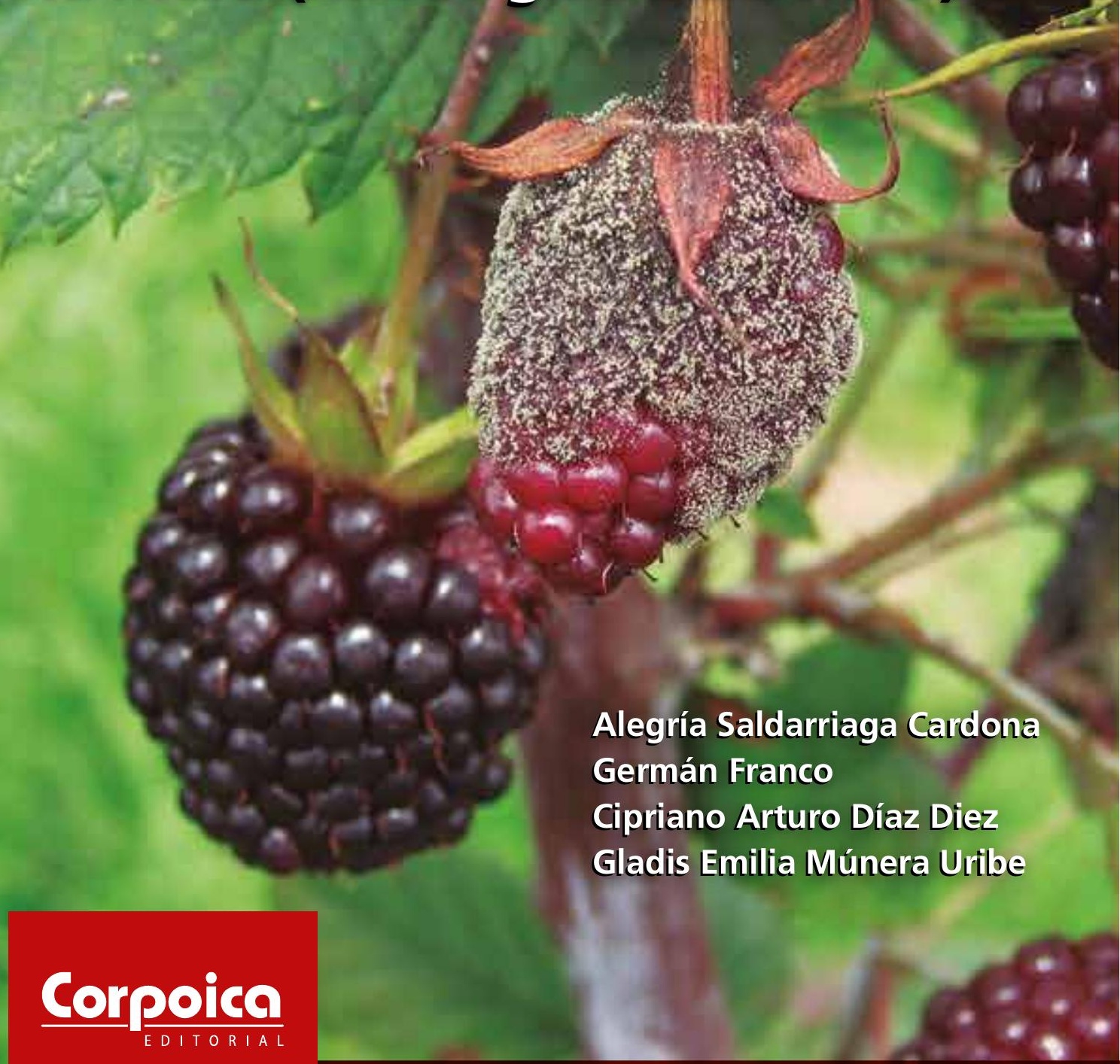

Colección Transformación del Agro 


\section{Manual de campo para reconocimiento, monitoreo y manejo de las enfermedades de la mora (Rubus glaucus Benth.)}

Alegría Saldarriaga Cardona

Germán Franco

Cipriano Arturo Díaz Diez

Gladis Emilia Múnera Uribe

\section{Corpoice}


Manual de campo para reconocimiento, monitoreo y manejo de las enfermedades de la mora (Rubus glaucus Benth.) / Alegría Saldarriaga Cardona [y otros tres]. -- Mosquera (Colombia) : Corporación Colombiana de Investigación Agropecuaria (Corpoica), 2017.

72 páginas

Incluye referencias bibliográficas

ISBN obra impresa: 978-958-740-242-1

ISBN (e): 978-958-740-243-8

1. Rubus glaucus Benth. 2. Enfermedades de las plantas 3. Síntomas 4. Gestión de lucha integrada 5. Pérdidas de la cosecha I. Saldarriaga Cardona, Alegría II. Franco, Germán III. Díaz Diez, Cipriano Arturo IV. Múnera Uribe, Gladis Emilia.

Palabras clave normalizadas según Tesauro Multilingüe de Agricultura Agrovoc Catalogación en la publicación - Biblioteca Agropecuaria de Colombia

Corporación Colombiana de Investigación Agropecuaria Corpoica

Centro de Investigación La Selva. Kilómetro 7, vía a Las Palmas, vereda Llanogrande, Antioquia. Código postal 054040, Colombia.

Primera edición: 2.000 ejemplares

Impreso en Bogotá, Colombia, agosto de 2017

Printed in Bogota, Colombia

Preparación editorial

Editorial Corpoica

editorial.corpoica@corpoica.org.co

Editora: Liliana Gaona García

Corrección de estilo: Eduardo Franco Martínez

Fotografías: Alegría del Socorro Saldarriaga Cardona

Ilustraciones: Juan Felipe Martínez Tirado

Impreso por: Fundación Cultural Javeriana de Artes

Gráficas (Javegraf)

Diseño y diagramación: Oficina Asesora de Comunicaciones, Identidad y Relaciones Corporativas, Corpoica

Citación sugerida: Saldarriaga-Cardona A, Franco G, Díaz-Diez CA, Múnera-Uribe GE. 2017. Manual de campo para reconocimiento, monitoreo y manejo de las enfermedades de la mora (Rubus glaucus Benth.). Mosquera, Colombia: [Corpoica] Corporación Colombiana de Investigación Agropecuaria.

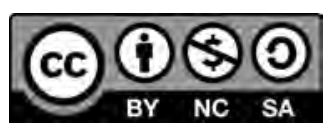

https://co.creativecommons.org/?page_id=13
Cláusula de responsabilidad: Corpoica no es responsable de las opiniones e información recogidas en el presente texto. Los autores asumen de manera exclusiva y plena toda responsabilidad sobre su contenido, ya sea este propio o de terceros, declarando en este último supuesto que cuentan con la debida autorización de terceros para su publicación; igualmente, declaran que no existe conflicto de interés alguno en relación con los resultados de la investigación propiedad de tales terceros. En consecuencia, los autores serán responsables civil, administrativa o penalmente, frente a cualquier reclamo o demanda por parte de terceros relativa a los derechos de autor u otros derechos que se hubieran vulnerado como resultado de su contribución.

Nota: En el presente documento, la mención de productos comerciales o ingredientes activos que no están registrados para su uso en el cultivo de mora, obedece a experiencias de investigadores, técnicos y productores, quienes los han utilizado y obtenido buenos resultados. Además, la alusión de algunos plaguicidas y fertilizantes no constituye garantía por parte de la Corporación Colombiana de Investigación Agropecuaria (Corpoica), como tampoco implica que se excluyan otros productos de igual o mayor eficiencia.

Línea de atención al cliente: 018000121515 atencionalcliente@corpoica.org.co www.corpoica.org.co 
Esta publicación es resultado de los proyectos:

"Cultivos de mora (Rubus glaucus Benth.), lulo (Solanum quitoense Lam.), tomate de árbol (Cyphomandra betacea (Cav.) Sendth.), guayaba (Psidium guajava L.) y maracuyá (Passiflora edulis Sims.), identificados, espacializados y caracterizados en el área geográfica de influencia del proyecto 'Modelo de plataforma para el aprovechamiento integral, adición de valor y competitividad de frutales comerciales andinos' 2014-2019”. Convenio específico de coejecución N. 11 entre la Universidad Nacional de Colombia y la Corporación Colombiana de Investigación Agropecuaria, julio de 2014.

"Diez genotipos de mora identificados por calidad (grados brix, acidez, tamaño de fruto y rendimiento)". Código Corpoica 1781, convenio 211 de 2012 MADR-Corpoica, marzo 2013.

"Actualización y transferencia sobre el manejo integrado de los cultivos de lulo, uchuva y mora con énfasis en el componente fitosanitario, para los productores y asistentes técnicos de Antioquia y eje cafetero". Código Corpoica C03113, convenio 069 de 2011 MADR-Corpoica componente tres, 2012. 
7 is

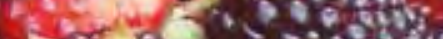

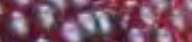

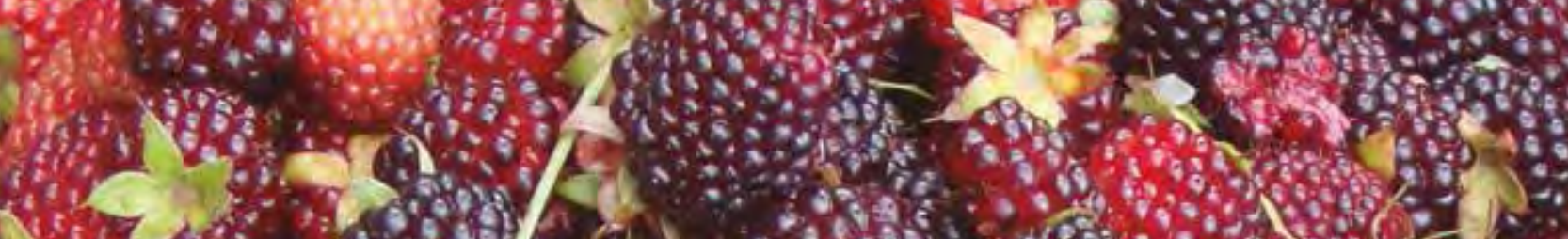

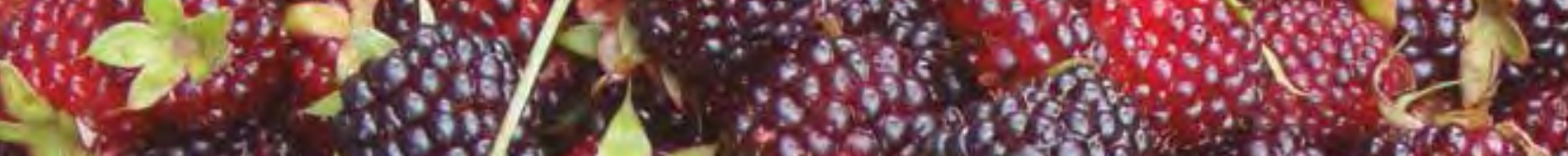
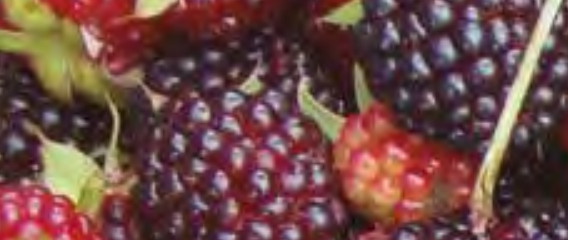

)
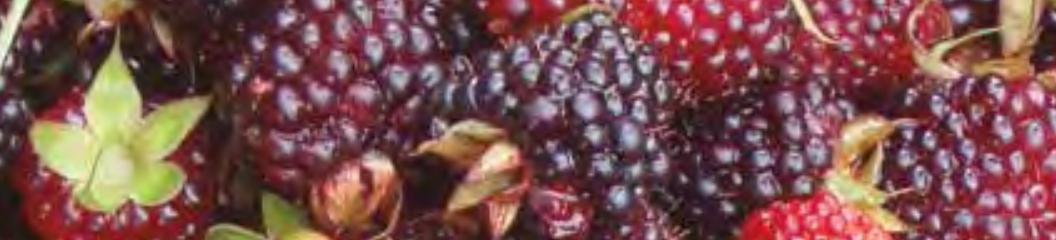

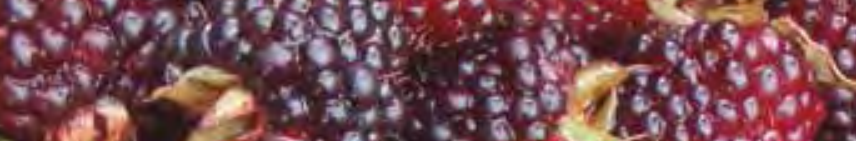

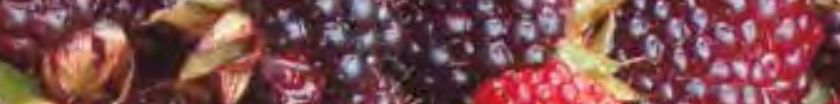
1.

(2) (1)

- $\sqrt{3}$

1005 tis

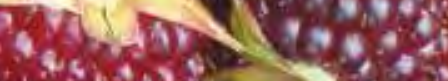

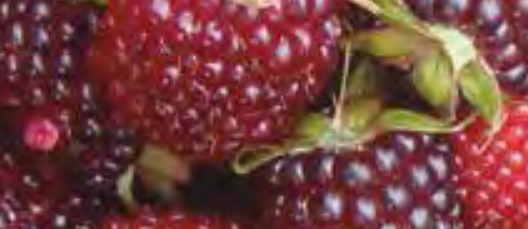

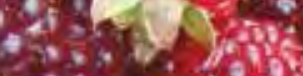
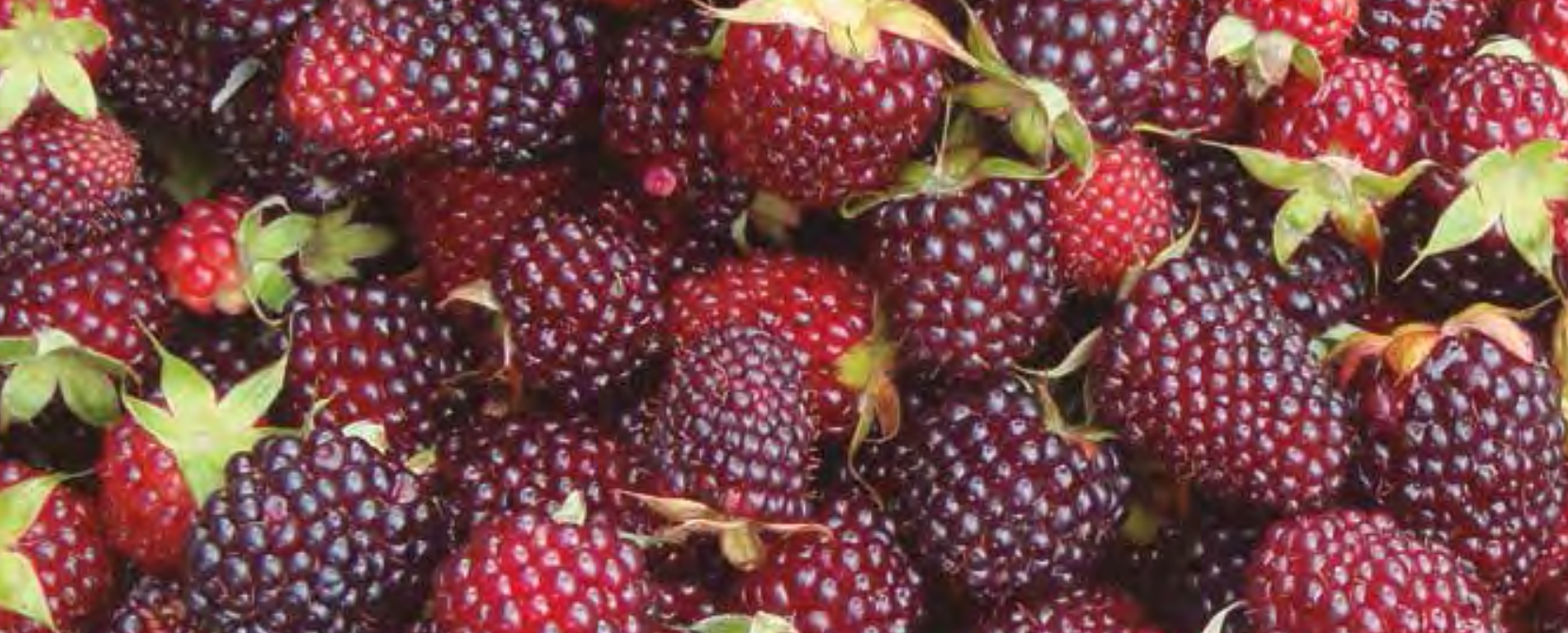

丽

$3 \sin ^{2}-21$ $x \rightarrow, y^{2}$

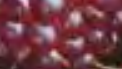

2. 8 हो.

$3: 30,0,05$

sove

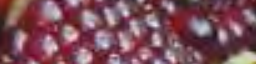

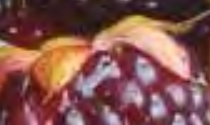

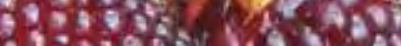

$3 ; 3,090$

$2: 3$.

ratosin

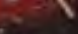

,

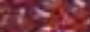

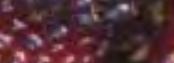

.

3.9. 9.69

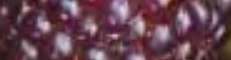

a.t.

$\therefore$
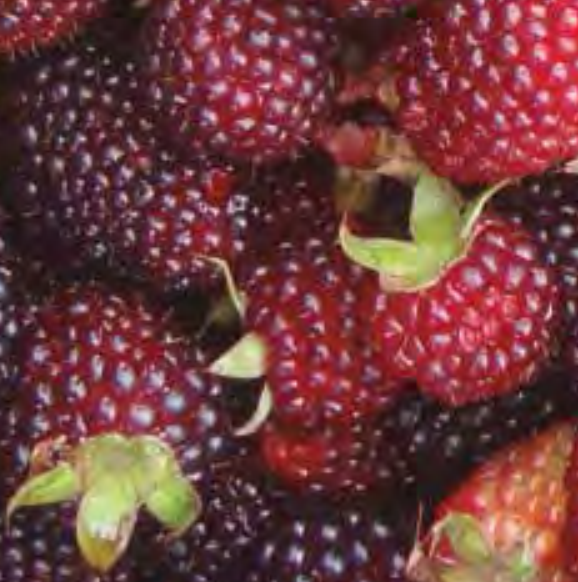

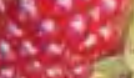

$(4) \frac{x^{2}}{9}$

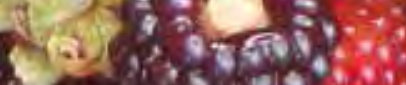

$\lim ^{2} x^{2}+x^{2}$

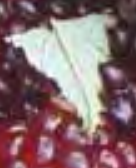

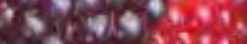

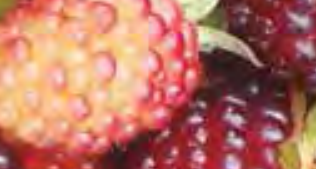

crosto $720 \%$

te 809 and

If 9090 ines

$\therefore ;: 418$

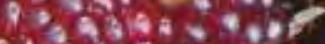

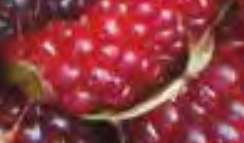

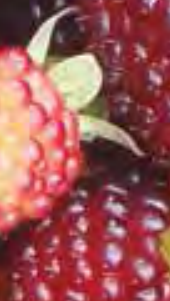

a.9.8?

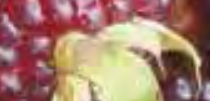

IV rop

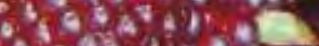

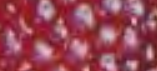

$+3$

$\log ^{2}+3,3$

$\lim ^{4}$
c.

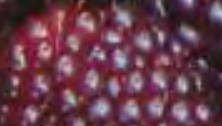

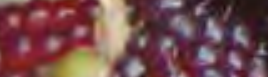
$x^{2}=$
1.
sois 3 a

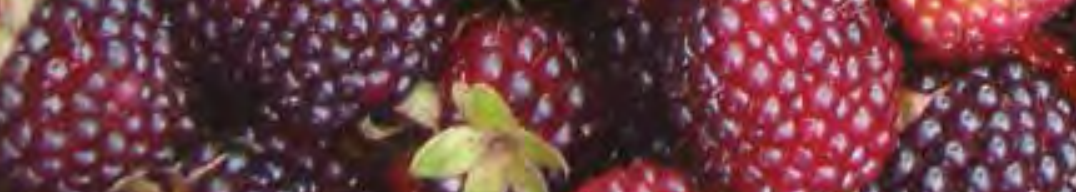

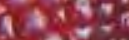

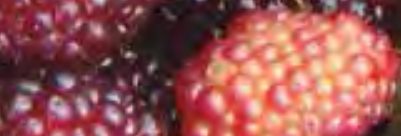

\section{Frutos de mora}

$+$,

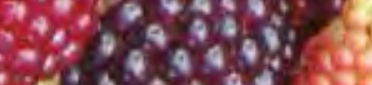

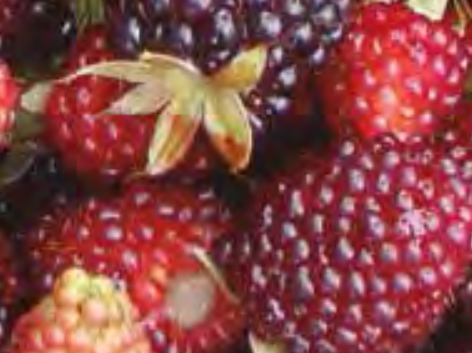
\& $30 \% 0 \%$ 


\section{Contenido}

$\begin{array}{ll}\text { Agradecimientos } & 13\end{array}$

$\begin{array}{ll}\text { Presentación } & 15\end{array}$

$\begin{array}{ll}\text { Introducción } & 17\end{array}$

\section{Capítulo I}

Aspectos generales sobre enfermedad, epidemia y cuantificación de enfermedades

\section{Capítulo II}

Principales enfermedades de la mora y consideraciones para el manejo

Antracnosis, tuna negra, muerte descendente 24

$\begin{array}{ll}\text { Síntomas } & 24\end{array}$

Monitoreo de la enfermedad $\quad 28$

Manejo integrado de la antracnosis $\quad 30$

Mildeo velloso, peronospora, tusa 32

Síntomas $\quad 32$

Monitoreo de la enfermedad 34

Manejo integrado del mildeo velloso 35

$\begin{array}{ll}\text { Mildeo polvoso, cenicilla, crespera } & 38\end{array}$

$\begin{array}{ll}\text { Síntomas } & 38\end{array}$

Monitoreo de la enfermedad $\quad 40$

Manejo integrado de mildeo polvoso, cenicilla, crespera 42

Moho gris, botrytis, pudrición del fruto 44

$\begin{array}{ll}\text { Síntomas } & 44\end{array}$

Monitoreo de la enfermedad 44

Manejo integrado del moho gris 46 


\section{Anexo}

Ejercicio para calcular incidencia y severidad de antracnosis, mildeo velloso, mildeo polvoso y moho gris en plantaciones de mora (Rubus glaucus Benth.)

Mildeo velloso, incidencia y severidad en tallos

Mildeo velloso, incidencia en frutos

Mildeo polvoso, incidencia en hojas

Mildeo polvoso, severidad en hojas

Mildeo polvoso, incidencia en estructuras reproductivas (botones

florales, flores y frutos

Moho gris en frutos, incidencia en frutos

Interpretación de resultados

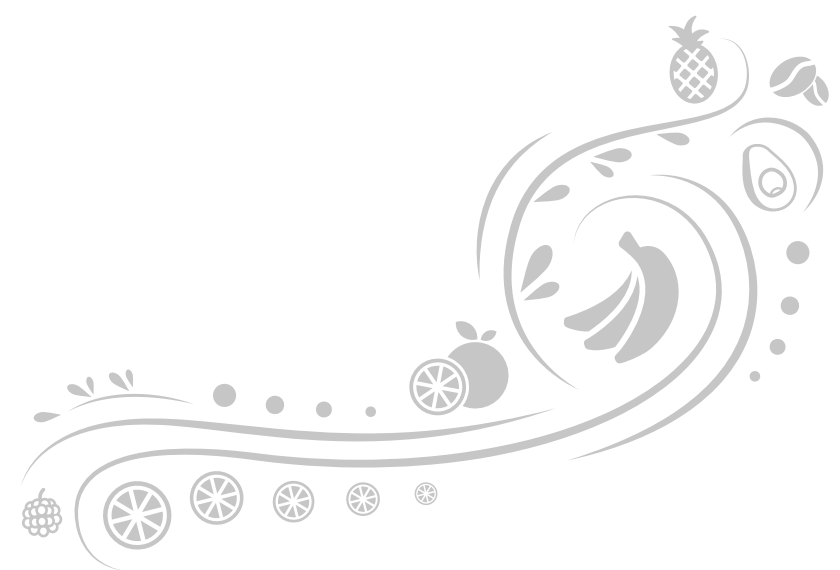




\section{Lista de figuras}

Figura 1 Síntomas de antracnosis en diferentes órganos de la planta

27 de mora

Figura 2 Ilustración de un patrón de selección de plantas para el monitoreo de enfermedades

Figura 3 Ilustraciones que representan diferentes niveles de severidad de antracnosis en tallos de mora

Figura 4 Síntomas de mildeo velloso en diferentes órganos de la planta de mora

Figura 5 Niveles de severidad de mildeo velloso en tallos de mora 34

Figura 6 Síntomas de mildeo polvoso en diferentes órganos de la 39 planta de mora

Figura 7 Niveles de severidad de mildeo polvoso en hojas de mora 41

Figura 8 Síntomas de moho gris en frutos de mora

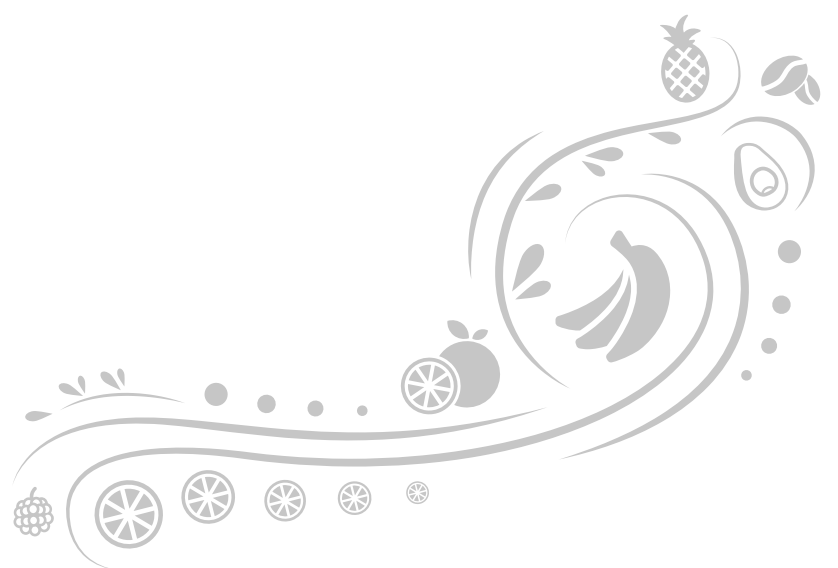




\section{Lista de tablas}

Tabla $1 \quad$ Niveles de severidad de antracnosis y acciones para el 31 manejo integrado

Tabla 2 Niveles de severidad de mildeo velloso y acciones para el manejo integrado

Tabla 3 Incidencia de mildeo velloso en frutos, significado y consideraciones para el manejo integrado de la enfermedad

Tabla 4 Niveles de severidad de mildeo polvoso en ramas y acciones sugeridas para el manejo

Tabla 5 Incidencia de moho gris en frutos y acciones sugeridas para el manejo

Tabla 6 Formato de campo para el cálculo de la incidencia de antracnosis en tallos de mora

Tabla 7 Formato de campo para el cálculo de la severidad de antracnosis en tallos de mora

Tabla 8 Formato de campo para el cálculo de la incidencia de 54 mildeo velloso en tallos de mora

Tabla 9 Formato de campo para el cálculo de la severidad de mildeo velloso en tallos de mora

Tabla 10 Formato de campo para registro y cálculo de la incidencia de mildeo velloso en frutos de mora

Tabla 11 Formato de campo para registro y el cálculo de la incidencia de mildeo polvoso en hojas de mora

Tabla 12 Formato de campo para el cálculo de la severidad de mildeo polvoso en ramas de mora 
Tabla 13 Formato de campo para el cálculo de la incidencia de mildeo polvoso en estructuras reproductivas de mora: botones florales, flores y frutos

Tabla 14 Formato de campo para registro y cálculo de la incidencia de moho gris en frutos de mora

Tabla 15 Reporte de niveles de incidencia y severidad para cuatro 60 enfermedades en mora

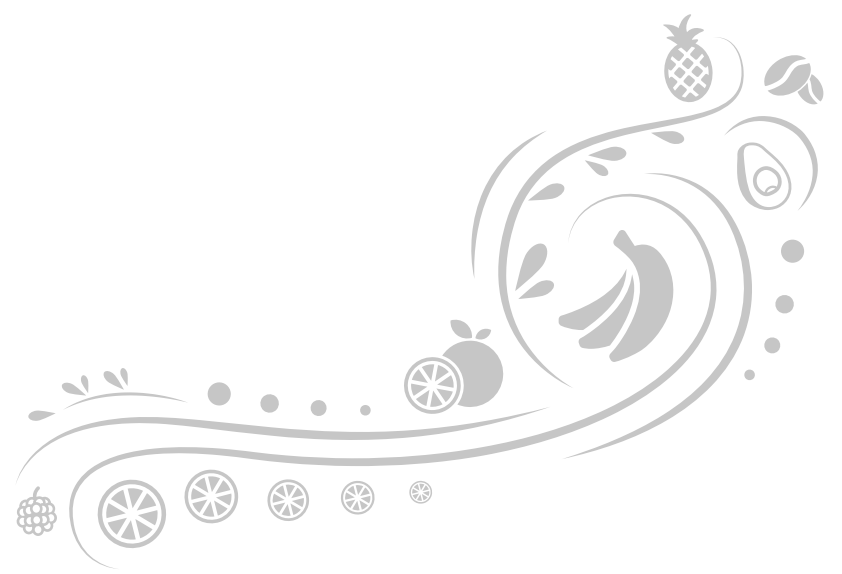



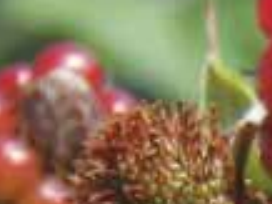

crestis.

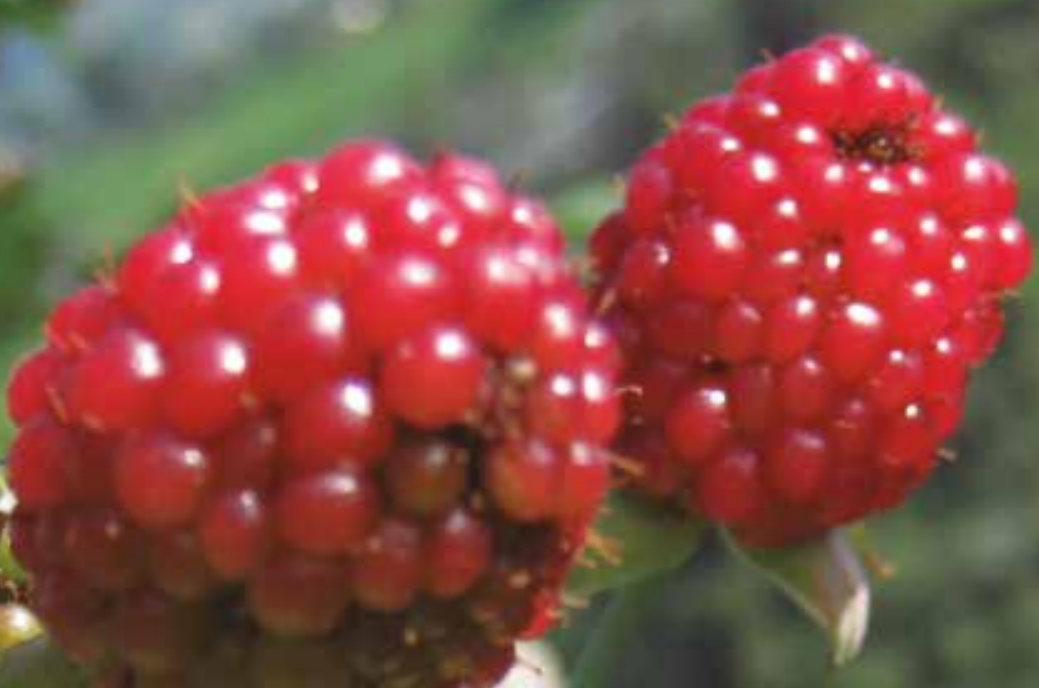

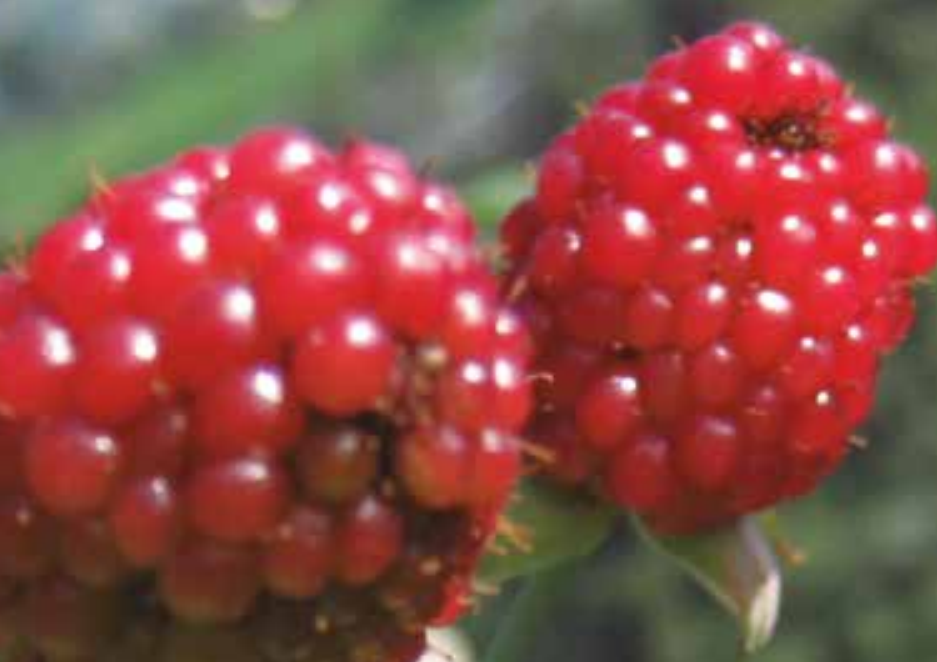

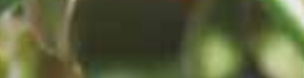

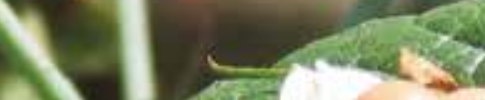

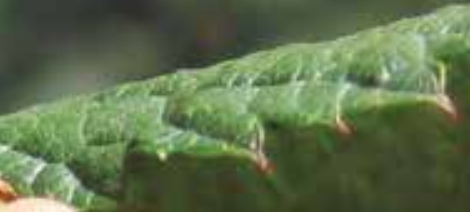

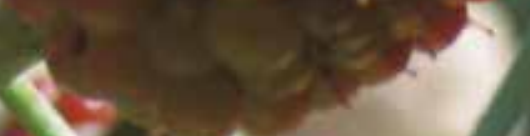

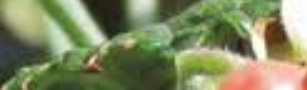

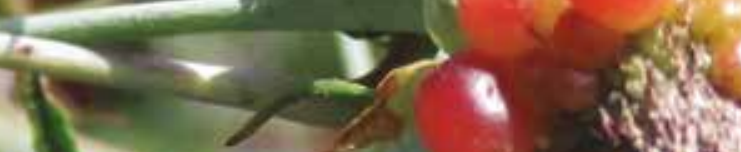
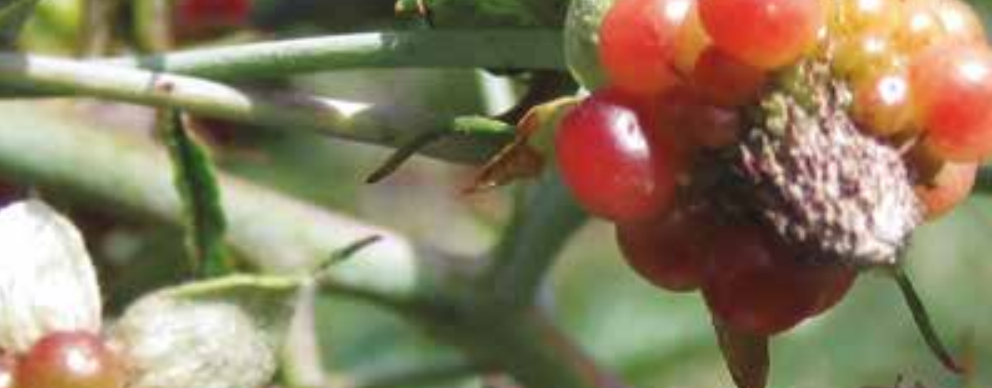

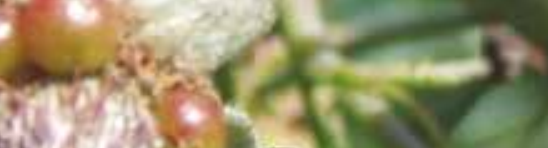

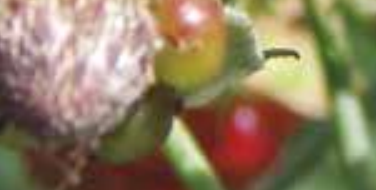

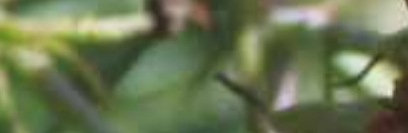

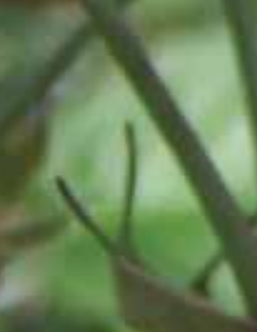

$$
\begin{aligned}
& 4
\end{aligned}
$$

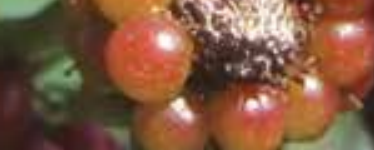

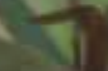

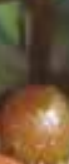

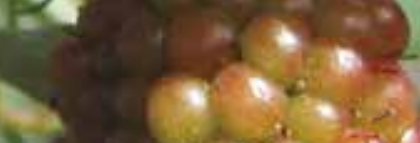

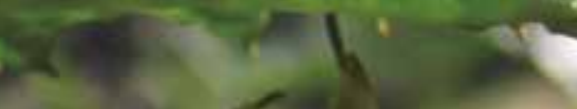

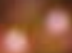




\section{Agradecimientos}

Los autores expresan su gratitud:

Al Ministerio de Agricultura y Desarrollo Rural de Colombia por su apoyo financiero para la realización de los proyectos que aportaron parte de los resultados para esta publicación.

Al Fondo Regional de Tecnología Agropecuaria (Fontagro) por su apoyo financiero para la realización de actividades de campo que aportaron parte de los resultados para esta publicación.

A la Universidad Nacional de Colombia sede Manizales, a Carlos Eduardo Orrego A. y Natalia Salgado A, por el liderazgo y apoyo para el desarrollo de las actividades técnicas y administrativas en el proyecto "Modelo de plataforma para el aprovechamiento integral, adición de valor y competitividad de frutales comerciales andinos".

A Germán Antía A., del Servicio Nacional de Aprendizaje (sENA), regional Caldas, por su acompañamiento y contribución en el desarrollo de actividades del campo.

A Albeiro Macías V., de la Corporación Colombiana de Investigación Agropecuaria (Corpoica), cI La Selva, por su apoyo en la realización de trabajos de campo y laboratorio.

A los productores de mora del oriente antioqueño y del Eje Cafetero por sus aportes tecnológicos, por facilitar los predios para el establecimiento de experimentos, toma de información y suministro de material vegetal para los estudios biológicos. 


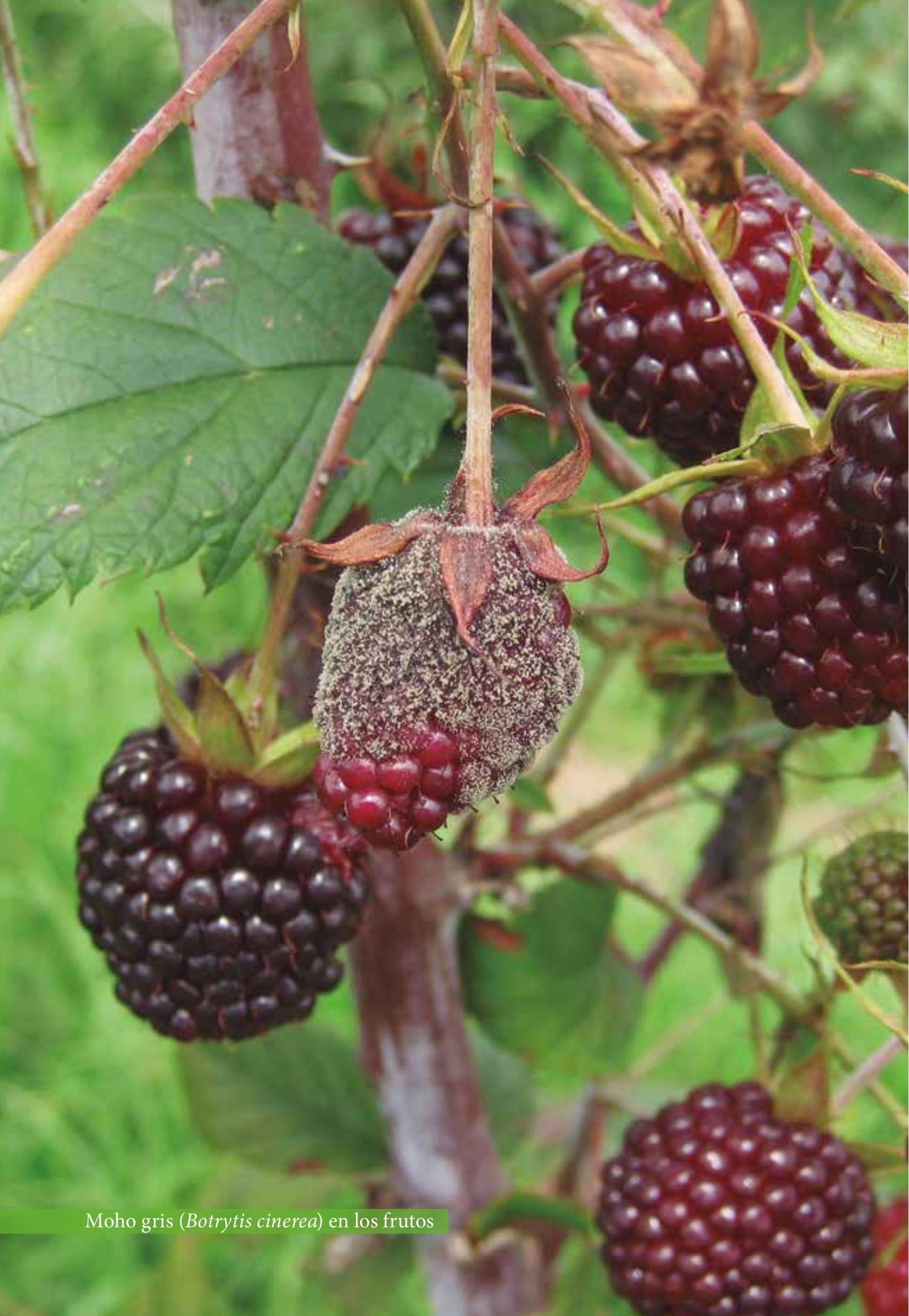




\section{Presentación}

La Corporación Colombiana de Investigación Agropecuaria (Corpoica), en el cumplimiento de su misión de contribuir al cambio técnico del sector agropecuario, entrega a los productores y asistentes técnicos del cultivo de la mora la publicación denominada Manual de campo para reconocimiento, monitoreo y manejo de las enfermedades de la mora (Rubus glaucus Benth.), que contiene descripciones e ilustraciones de las principales enfermedades que afectan este frutal y aporta metodologías para su cuantificación, orienta en la estimación de las pérdidas y su impacto económico, además de brindar recomendaciones técnicas para el manejo integrado de las enfermedades y el cultivo.

La mora es un cultivo que cuenta con gran aceptación para consumo como fruta fresca y procesada, sin embargo, los productores enfrentan diversos problemas, especialmente de tipo fitosanitario, que han llevado a que la producción no tenga los rendimientos y la calidad que demanda la industria, con lo que se pierden oportunidades de negocios. De hecho, las nuevas realidades del mercado orientan hacia la necesidad de una producción más eficiente y sostenible, con un uso racional de los plaguicidas para obtener fruta que cumpla con los estándares de calidad e inocuidad, además de contribuir a la conservación del ambiente y la salud de los productores.

Por tanto, contar con herramientas acertadas para el reconocimiento, el diagnóstico y la cuantificación de las enfermedades es fundamental para el desarrollo de estrategias de manejo del cultivo. Igualmente, la productividad del cultivo es un factor 
crítico para los productores que derivan su sustento de esta actividad, siendo importante el desarrollo de competencias para estimar pérdidas en la producción, valorar los ingresos por concepto de venta del producto y conocer el estado económico de la producción en cualquier momento que se requiera.

Estas consideraciones han motivado a Corpoica, con el apoyo del Ministerio de Agricultura y Desarrollo Rural (MADR) y el Fondo Regional de Tecnología Agropecuaria (Fontagro) para la elaboración de este manual de campo, con el propósito de proporcionar herramientas a los productores y asistentes técnicos que aporten a la mejora de la tecnología del cultivo. Además, se fundamenta en resultados de investigación, experiencias de productores y profesionales con trayectoria en el cultivo, obtenidos en el desarrollo de proyectos adelantados por Corpoica y otras instituciones.

Julián Alberto Londoño Londoño Director Centro de Investigación La Selva, Corpoica 


\section{Introducción}

Las enfermedades de la mora de Castilla (Rubus glaucus Benth.) son un factor limitante de la producción por los daños directos que ocasionan en las plantas, puesto que afectan los rendimientos, la vida útil del cultivo y los ingresos del productor debido al costo económico que representa el manejo (Díaz et al. 2009; Gaviria 2011). La demanda del producto, para consumo fresco y como materia prima para la agroindustria, ha motivado el aumento de las áreas cultivadas y propiciado el incremento en la incidencia y severidad de las enfermedades (Rodríguez et al. 2000; Tamayo y Peláez 2000; Botero y Franco 2007; Díaz et al.; 2009; Gaviria 2011). La necesidad de controlarlas obliga a los productores a la aplicación de numerosos productos agroquímicos, lo cual genera riesgos de contaminación ambiental y de la fruta, así como riesgos de salud para los productores y consumidores, puesto que las frutas no tienen la condición de inocuidad requerida (Díaz et al. 2009). Las recientes tendencias de producción de alimentos están orientadas hacia la obtención de productos con menor carga de plaguicidas, además de las exigencias sobre conservación ambiental e inocuidad de los alimentos. Actualmente, en el cultivo de la mora, se está empezando a restringir y prohibir el uso de algunas moléculas de fungicidas (Arroyave y Salazar s. f.; Zapata et al. 2013), debido al riesgo que presentan para la salud humana y el ambiente ${ }^{1}$. Esto ha generado la necesidad de racionalizar las aplicaciones, por lo cual, es necesario que técnicos y productores conozcan las enfermedades y las cuantifiquen para seleccionar la alternativa y estrategia de manejo por implementar, de acuerdo con el estado fenológico y fitosanitario de la plantación, el momento climatológico y las características biológicas del patógeno y la enfermedad. Este manual aporta orientación para el reconocimiento de los síntomas de las diferentes enfermedades de la mora, brinda una herramienta para la cuantificación mediante el uso de ilustraciones (diagramas de severidad de enfermedades) y ofrece recomendaciones técnicas para el manejo integrado de las principales enfermedades de la mora en Colombia.

\footnotetext{
${ }^{1}$ Información procedente de bases de datos de informe interno de Asohofrucol-Risaralda, de circulación restringida.
} 


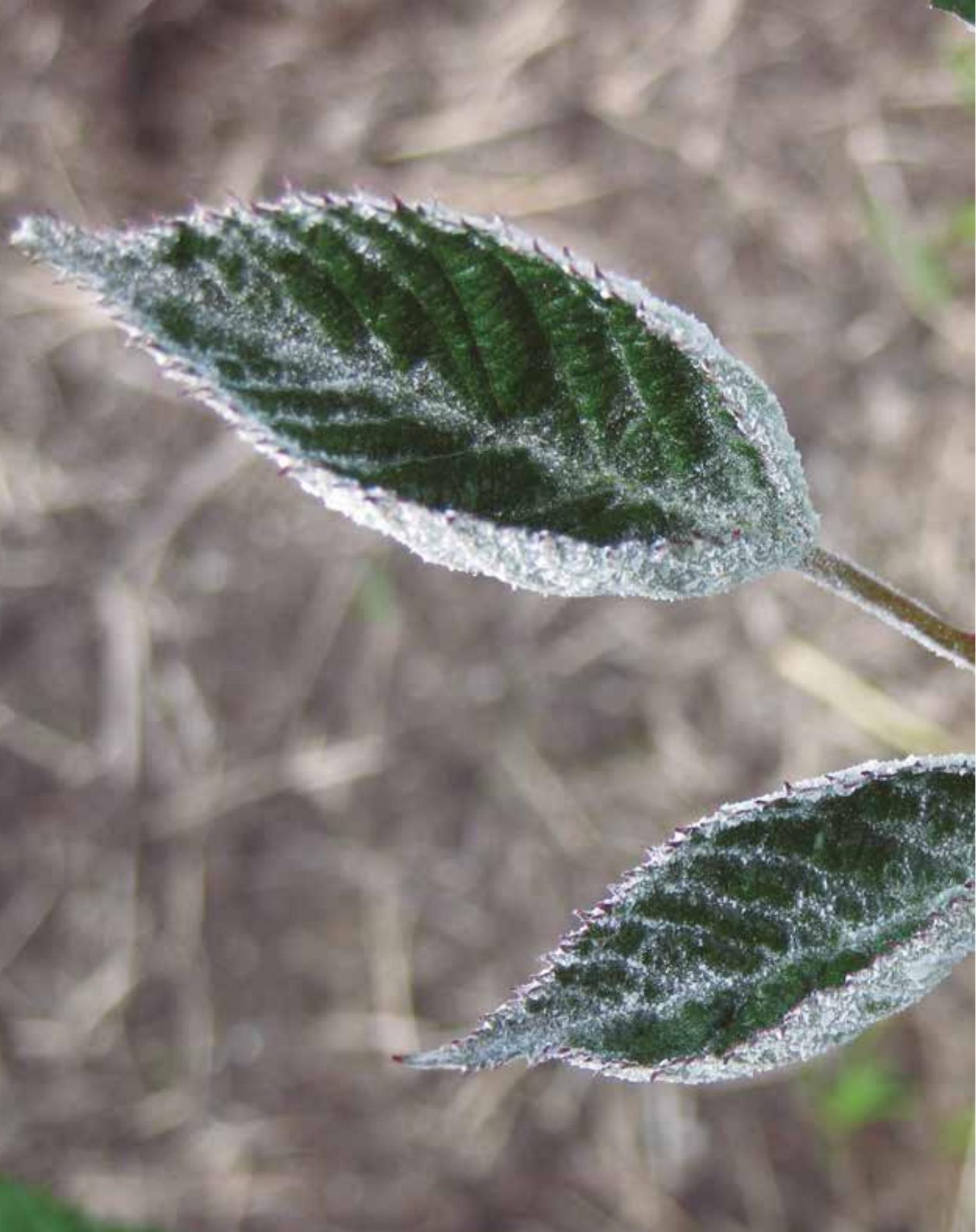




\section{Aspectos generales sobre enfermedad, epidemia y cuantificación de enfermedades}

Una enfermedad es el resultado de la interacción dinámica entre un hospedante (planta), un patógeno y el medio ambiente, que en el hospedante se traduce en un desorden fisiológico o en una anormalidad estructural que afecta la capacidad funcional y hace que la planta no produzca de acuerdo con su potencial genético (Castaño 1994; Pérez 1994; Castaño 2002).Además, una epidemia es el desarrollo amplio y destructivo de una enfermedad que afecta numerosos individuos de una población (Pérez 1994), que solo se presenta cuando las plantas son susceptibles, el agente causante está presente y el ambiente es favorable. Cuando estos tres elementos permanecen juntos en sus condiciones óptimas durante un tiempo suficiente, se desarrollan los eventos biológicos que conducen al incremento de la enfermedad y a la generación de la epidemia. Si se pretende mantener un cultivo sano, es necesario aprender a manejarlo de tal forma que se evite la ocurrencia de epidemias y se mantengan las enfermedades en niveles que no causen pérdidas económicas, lo cual se puede alcanzar con la utilización de tres estrategias: 1. con el cambio del hospedero (uso de genotipos con resistencia genética); 2. al modificar 
el ambiente (realización de prácticas que contribuyan a la generación de condiciones adversas al patógeno y al desarrollo de la enfermedad); y 3. en mantener los patógenos bajo control durante el tiempo necesario para sacar adelante la producción (Castaño 2002).

Para lograr lo anterior, se deben considerar algunas medidas generales: es fundamental el diagnóstico y el reconocimiento de las enfermedades y la cuantificación de estas para hacer la selección y el uso de las prácticas y los métodos de control de manera apropiada, oportuna y compatible (Castaño 1994). La cuantificación requiere el monitoreo periódico de las enfermedades en el cultivo para determinar el estado sanitario, el progreso de las enfermedades en el tiempo, el monto de las pérdidas potenciales y la definición de las medidas de manejo por aplicar, con el propósito de prevenir, demorar o disminuir el proceso epidémico, de tal manera que se pueda reducir el efecto que las enfermedades causan sobre los rendimientos (Castaño 1994; Pérez 1994; Castaño 2002). La cuantificación de las enfermedades no es sencilla y aplica consideraciones relacionadas con atributos y fenología del cultivo, atributos del patógeno, determinantes ambientales y habilidad del evaluador para detectar e interpretar las variaciones y su significado.

Para medir la presencia de una enfermedad en una población de plantas, lo mejor es acudir a métodos o herramientas directos, en los que se aprecie cuántas plantas están enfermas (incidencia) y qué tan enfermas están (severidad). En campo, comúnmente, se procede a realizar muestreos en el cultivo y, si se considera la planta como unidad de medida, entonces la incidencia de una enfermedad es la proporción o el porcentaje de plantas con síntomas visibles de la enfermedad evaluada, con relación al número total de unidades estimadas, y se puede representar así:

Incidencia $=\frac{\text { (Número de plantas enfermas) }}{\text { Número total de plantas observadas (sanas+enfermas) }}$

La incidencia también se define como el número de unidades enfermas por unidad de medida. Se pueden considerar como unidades el número de plantas, las ramas individuales, las hojas, los tallos, los frutos o las raíces enfermas por surco o parcela. Este es el sistema más fácil y rápido para medir el daño causado por las enfermedades. 
La severidad se refiere al área de tejido de la planta que está afectada por la enfermedad y se puede expresar como porcentaje. Para estimar la severidad, se utilizan escalas y diagramas estándares (serie de ilustraciones de niveles de severidad de una determinada enfermedad), con los cuales se comparan las estructuras afectadas (hojas, tallos, por ejemplo), y se determina el porcentaje real de tejido enfermo (Pérez 1994; Castaño 1994; Castaño 2002). La escala contempla categorías y descripciones y se construye al dividir el rango total de posible severidad de una determinada enfermedad en categorías o clases. Escala y diagrama se complementan, de tal forma que los diagramas ilustran ciertos niveles de severidad de una enfermedad, que pueden corresponder a intervalos o clases de una escala. La utilidad de estos métodos o herramientas es que permiten relacionar incidencia o severidad con pérdidas de la producción comercializable.

No obstante, a menudo se encuentra que los datos sobre pérdidas en un cultivo son solo estimativos. La dificultad radica en el hecho de que las plantaciones se establecen en una amplia gama de ambientes, sobre diversos tipos de suelos, con diferentes niveles de nutrientes, bajo diferentes regímenes de temperatura y humedad. Como consecuencia, los rendimientos varían de una región a otra y se hace difícil determinar cuánta de esta variación se debe a las condiciones del cultivo y cuánta a las enfermedades (Castaño 1994; Castaño 2002).

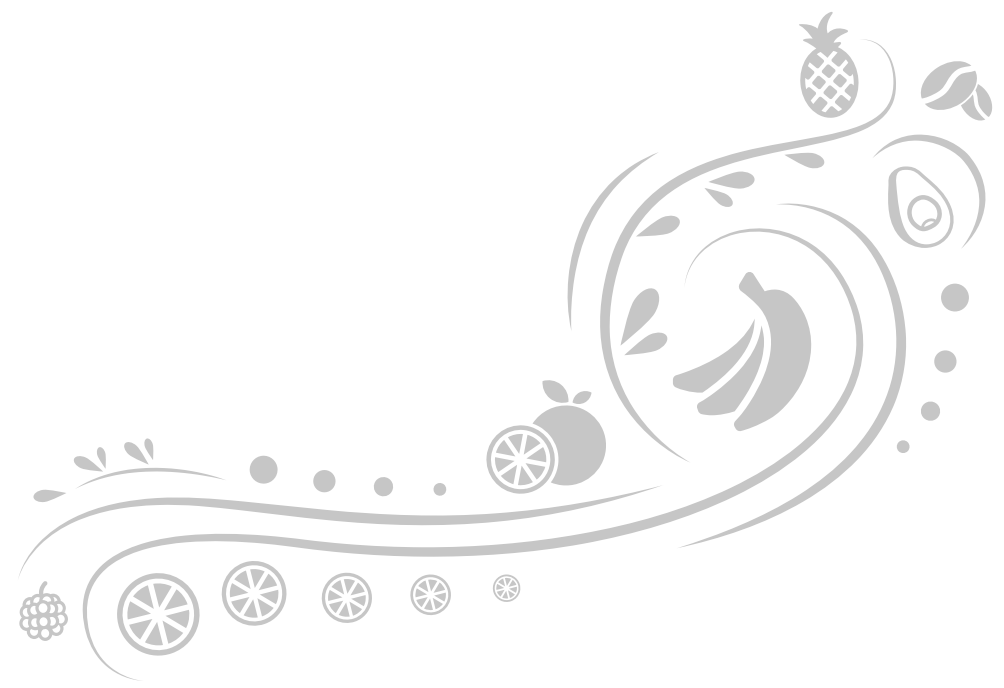





\section{Principales enfermedades de la mora y consideraciones para el manejo}

La mora es afectada por enfermedades que atacan diferentes estructuras de la planta, como raíces, tallos, hojas, botones florales, flores y frutos, las cuales se favorecen por condiciones, como material de propagación de mala calidad, humedad relativa alta, abundancia de malezas en la plantación, falta de podas, deficiencias nutricionales, falta de labores culturales oportunas y apropiadas y susceptibilidad de los materiales (Saldarriaga y Bernal 2000; Tamayo 2003; Hincapié 2010; Betancourt et al. 2014).

El manejo integrado de las enfermedades de la mora contempla los factores: hospedante, patógeno y clima (ambiente), y se fundamenta en los principios de exclusión, erradicación y protección. El hospedante se maneja con el uso de material de buena calidad, tolerante a enfermedades, con la fertilización adecuada y el empleo de productos químicos. El patógeno se puede intervenir mediante la aplicación de medidas de exclusión; por ejemplo, evitar la movilización de material infectado por una determinada enfermedad hacia zonas libres de esta, por erradicación de plantas o cultivos afectados para 
impedir el avance de una enfermedad; y mediante la reducción de inóculo con la realización de podas sanitarias, destrucción de restos de material afectado, desinfestación de herramientas y uso de controles biológicos y químicos. El clima (microclima del cultivo) se puede modificar con el uso de distancias de siembra y la realización de podas que permitan la circulación del aire dentro de la plantación, para ayudar a la evaporación de las láminas de agua en los tejidos vegetales y así desfavorecer los procesos biológicos de los patógenos; también, con el control de malezas, realización de drenajes, aplicación de riego (en temporadas de sequía) y rotación de cultivos (Pérez 1994; Franco y Giraldo 2002; Mesa et al. 2014).

Para el manejo integrado de las enfermedades, se debe hacer uso de los métodos de control cultural (prácticas de cultivo), biológico, genético y químico. La integración de los diferentes métodos de control es la forma más adecuada de obtener cultivos sanos y con producción de buena calidad, por lo que la realización de una práctica de control única y aislada no ofrece las posibilidades de éxito que sí se puede tener cuando se aplican de manera integrada y oportuna diferentes estrategias de manejo (Castaño 1994; Pérez 1994; Tamayo 2003).

A continuación, se relacionan las principales enfermedades causadas por hongos que afectan la mora. Se hace alusión a los agentes causales, los síntomas que expresan los diferentes órganos de la planta cuando son afectados, se presentan las metodologías para la cuantificación de las enfermedades y se sugieren recomendaciones para el manejo integrado.

\section{Antracnosis, tuna negra, muerte descendente}

Esta enfermedad es ocasionada por Glomerella cingulata (Stoneman.) Spauld. \& Schrenk. (anamorfo Colletotrichum gloeosporioides (Penz.) Penz. \& Sacc.), Colletotrichum acutatum Simmonds., Colletotrichum boninense Moriw., Sato \& Tsukib. (Saldarriaga et al. 2002; Saldarriaga 2006; Saldarriaga et al. 2008; Afanador et al. 2009; Rueda 2010; Rueda et al. 2012; Saldarriaga et al. 2012).

\section{Síntomas}

Las especies de hongos que causan esta enfermedad se manifiestan principalmente en tallos, brotes y estructuras reproductivas, con la producción de lesiones que pueden conllevar la muerte de las ramas. Los tallos afectados presentan manchas ovaladas 
de color morado a café oscuro sobre las cuales aparecen puntos diminutos de color negro con masas de color amarillo intenso correspondientes a la esporulación del hongo, síntoma que se denomina lesión de tallo. Las manchas cubren parcialmente el tallo y progresan en su tamaño hasta comprometer gran parte de este (figura 1a), la rama se marchita, las hojas se tornan amarillas y se secan adheridas al tallo, posteriormente la rama muere (figuras 1b, 1c) (Saldarriaga 2006; Saldarriaga et al. 2008; Afanador et al. 2009; Tamayo 2009; Rueda 2010). En otras ocasiones, la enfermedad se manifiesta con lesiones claras alrededor de las espinas o aguijones (figura 1d), sobre las cuales aparecen pequeños puntos negros acompañados de masas diminutas de color amarillo (esporulación del hongo), síntoma que se conoce como tuna negra. Los hongos causantes de la antracnosis también pueden afectar inflorescencias, brotes tiernos y frutos (Botero et al. 1999; Franco y Giraldo 2002; Ávila et al. 2003; Saldarriaga et al. 2012). En las inflorescencias, la enfermedad se manifiesta con producción de necrosis (muerte de las células) de los tejidos (figura 1e), sobre los cuales esporula el hongo (Rueda 2010). En los brotes tiernos, se observa ennegrecimiento (figura 1f) y las ramas mueren en forma descendente progresiva (Castro y Díaz 2001). La enfermedad se encuentra esporádicamente en frutos maduros, los cuales presentan deshidratación, necrosis y pudrición húmeda (figura 1g), con presencia de estructuras del hongo (Saldarriaga y Bernal 2000; Botero et al. 2002).

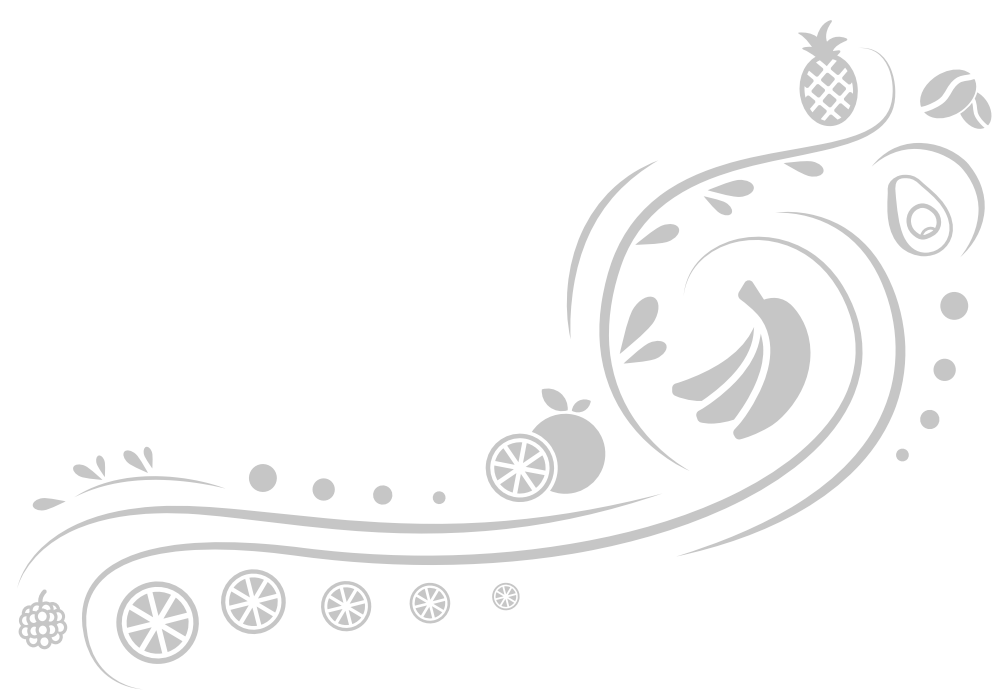




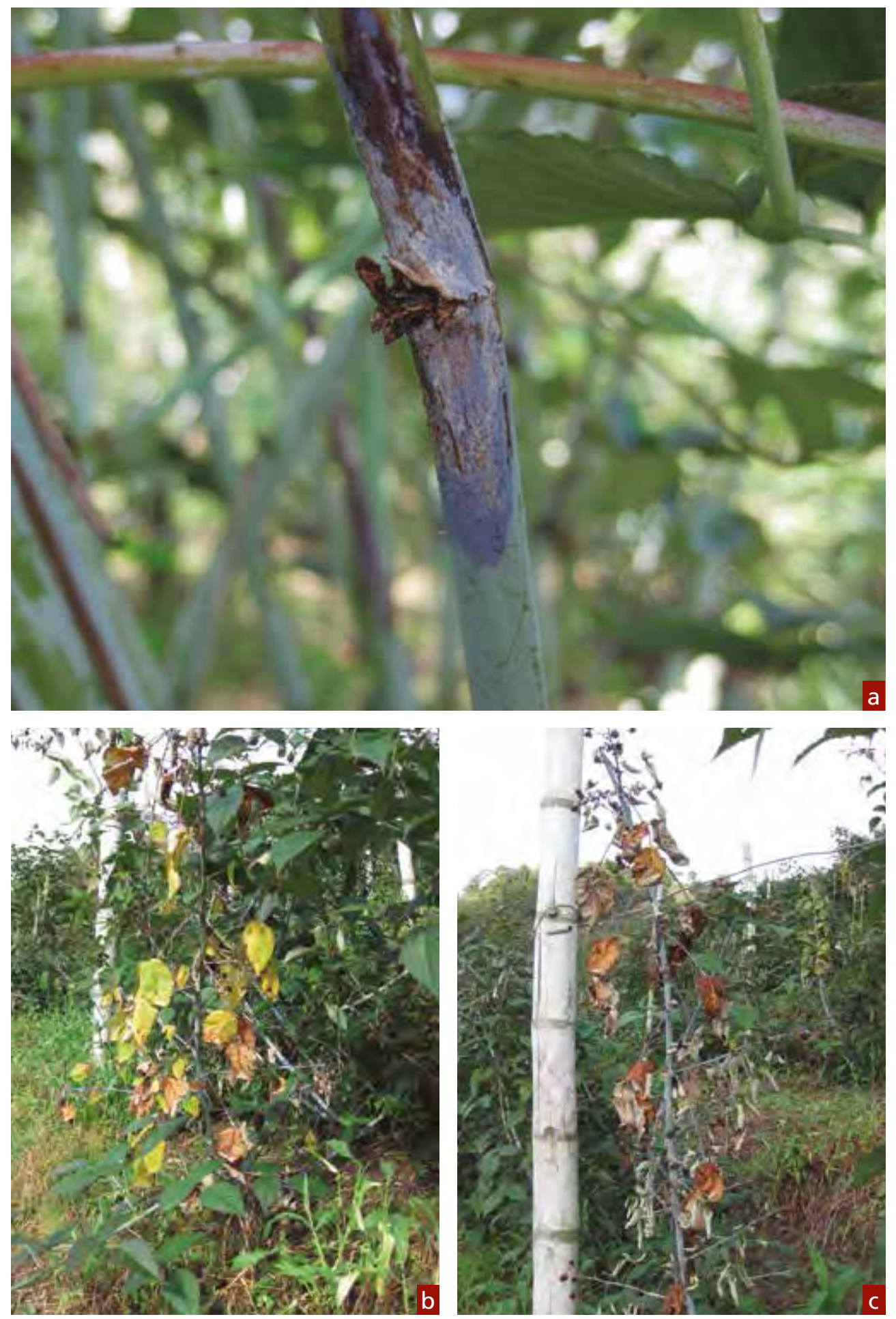



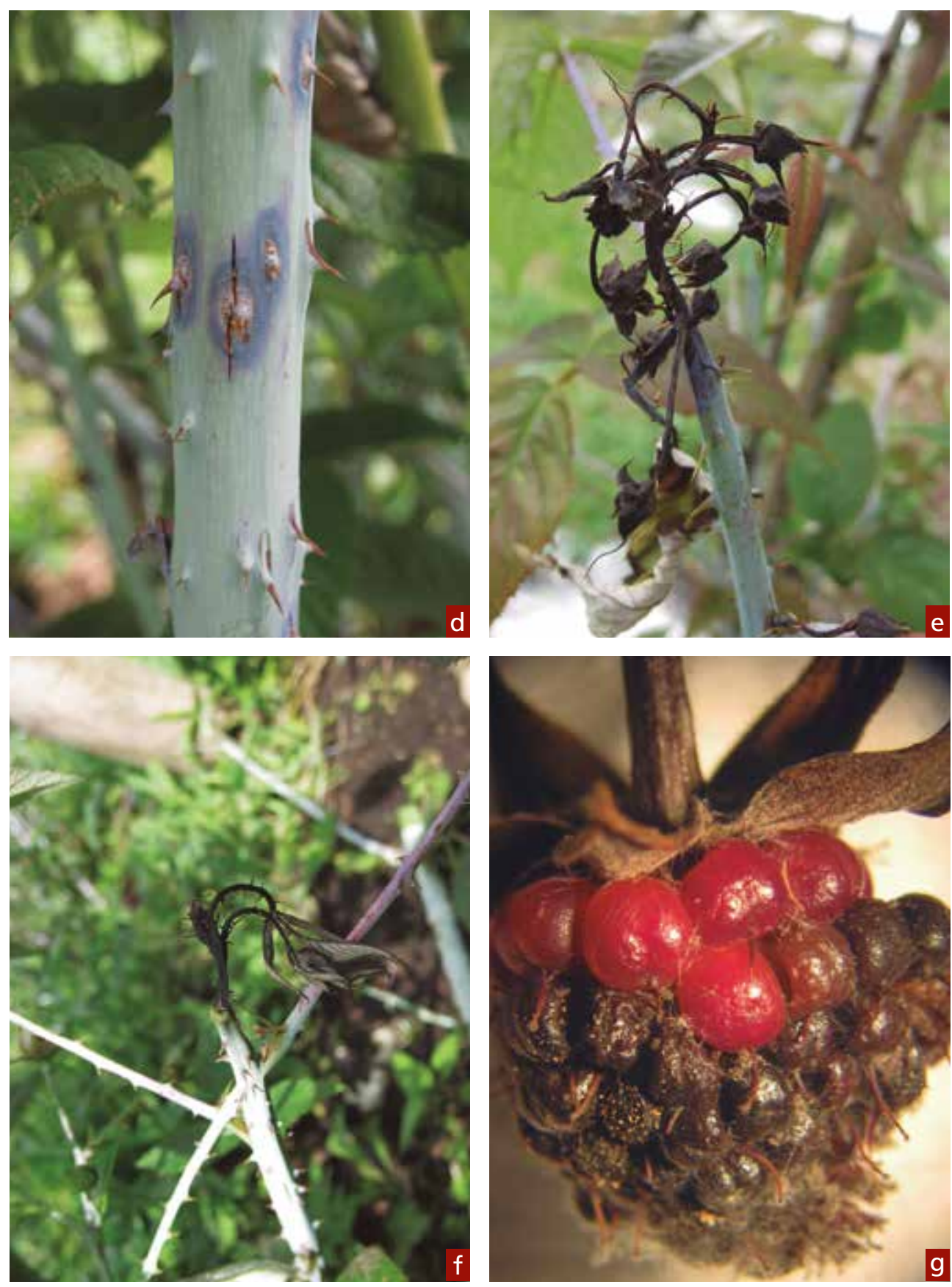

Figura 1. Síntomas de antracnosis en diferentes órganos de la planta de mora. a. Síntoma conocido como lesión de tallo; b. Amarilleamiento progresivo de hojas; c. Rama muerta; d. Síntoma conocido como tuna negra; e. Necrosis de las inflorescencias; f. Muerte descendente de los brotes; g. antracnosis en frutos. 


\section{Monitoreo de la enfermedad}

La enfermedad se ve favorecida en cultivos con densidades altas de siembra, humedad relativa alta, enmalezados y sin podar (Franco y Giraldo 2002; Tamayo 2003; Mesa et al. 2014).

Para la cuantificación, se deben inspeccionar los diferentes órganos de la planta con frecuencia semanal o quincenal, según las condiciones climatológicas, el estado del cultivo y el microclima de la finca. La revisión del cultivo (monitoreo) debe ser más frecuente en temporadas húmedas, cultivos establecidos con genotipos susceptibles, plantaciones con alta densidad o con más de cinco tallos por planta.

Para el monitoreo de la enfermedad, se selecciona el $10 \%$ de la población de plantas del cultivo, con la precaución de que se encuentren distribuidas en la parte alta, media y baja del lote (figura 2).
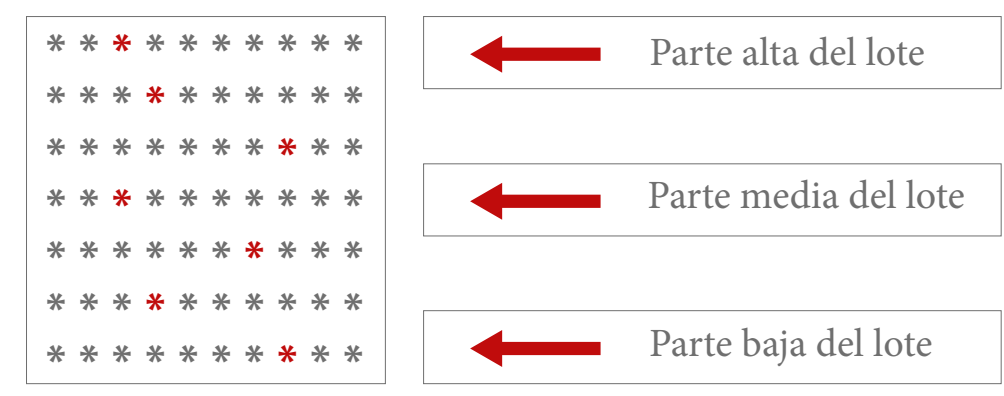

Figura 2. Ilustración de un patrón de selección de plantas para el monitoreo de enfermedades. En rojo las plantas por evaluar.

Fuente: Elaboración propia

En cada una de las plantas seleccionadas, se cuentan los tallos principales sanos y enfermos y se estima la incidencia (I) con la observación de lesiones en el tercio medio e inferior de ellos, para lo cual se aplica la ecuación 1:

$$
\begin{aligned}
& \text { Porcentaje de incidencia } \\
& \text { de antracnosis }(\mathrm{I})
\end{aligned}=\frac{\text { Número de tallos afectados por planta }}{\text { Número de tallos observados por planta }} \cdot 100
$$


De esta forma, se obtiene la incidencia por planta y se halla el promedio para el total de plantas muestreadas (anexo). La incidencia de esta enfermedad en frutos es baja, no supera el 10 \% (Tamayo y Peláez 2000; Díaz et al. 2013), por lo cual no se contempla su valoración en esta estructura. Para cuantificar la severidad (S), que se estima en $20 \mathrm{~cm}$ del tercio bajo de los tallos afectados de las plantas muestreadas, se implementa el uso de un diagrama (figura 3), que considera cuatro niveles de severidad, definidos por el porcentaje de área de tejido de tallo afectado por la enfermedad, así: nivel 1: $1 \%$ de tejido afectado; nivel 2: $2 \%$ de tejido afectado; nivel 3: $5 \%$ de tejido afectado; nivel 4: $10 \%$ o más de tejido afectado.

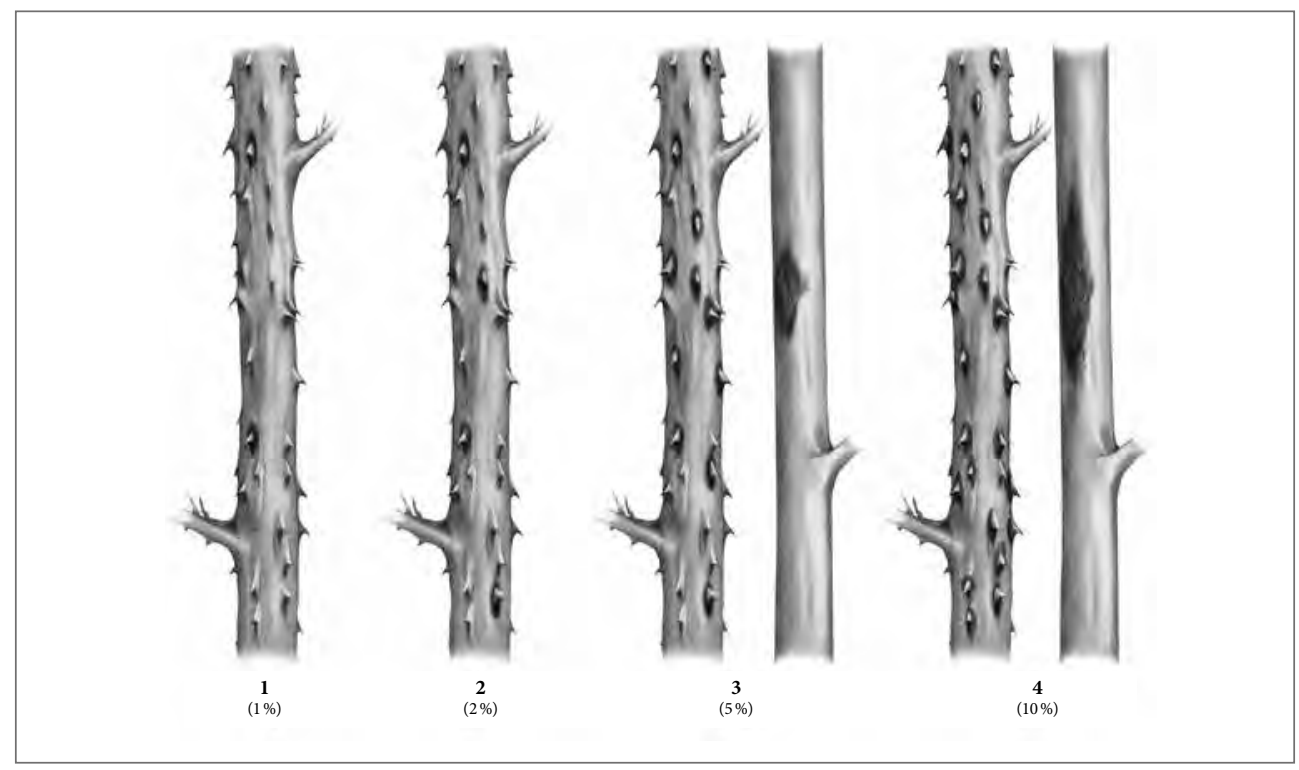

Figura 3. Ilustraciones que representan diferentes niveles de severidad de antracnosis en tallos de mora. En los niveles 3 y 4, se representan los dos síntomas (tuna negra a la izquierda y lesión de tallo a la derecha).

Fuente: Elaboración propia

Los estudios de campo 2007-2013 (Saldarriaga et al. 2012; Múnera et al. 2012; Saldarriaga 2012; Díaz et al. 2013) permitieron detectar que los niveles máximos de severidad de antracnosis en tallos de mora no superaban el $10 \%$, por lo cual se ajustó el diagrama y se amplió para las dos variantes de síntomas de la enfermedad en los tallos (tuna negra y lesión de tallo), por considerar que, en los genotipos de mora con espinas, se presenta tuna negra y, en los genotipos sin espinas, predomina el síntoma lesión de tallo. 
Con los valores obtenidos por planta, se determina la severidad media de la enfermedad en el cultivo (anexo) (Botero et al. 2003; Marulanda et al. 2011; Múnera et al. 2012; Saldarriaga 2012). Se considera un nivel bajo cuando es menor del $2 \%$, medio entre el $2 \%$ y el $10 \%$ y alto cuando es mayor del $10 \%$. El significado práctico consiste en que, a medida que se aumenta el área afectada en un tallo, la rama se debilita, se torna clorótica y puede llegar a morir y, en algunas ocasiones, se rompe por el sito donde se encuentra la lesión, lo cual le hace perder su potencial productivo.

En campo, se debe disponer de un formato para registrar la información correspondiente a las valoraciones de las incidencias y severidades de las diferentes enfermedades; luego, esta información se procesa y analiza como fundamento para la toma de decisiones de manejo fitosanitario en el cultivo (anexo).

\section{Manejo integrado de la antracnosis}

El manejo integrado se basa en la realización adecuada y oportuna de las prácticas de cultivo, principalmente las podas sanitarias de ramas con alta severidad de la enfermedad, podas de aireación y de ramas que ya produjeron, manejo de residuos de podas, control de malezas y fertilización, también se debe tener en cuenta el momento climatológico, la fenología del cultivo y los niveles de la enfermedad. Cuando la severidad supera el $2 \%$, se complementan las labores culturales con la aplicación de fungicidas en rotación a base de difenoconazol, carbendazim, azoxystrobin, tebuconazol, trifloxystrobin, y cobres, entre otros, que pueden controlar la enfermedad. La selección y aplicación de los fungicidas debe considerar el nivel de enfermedad en el cultivo (tabla 1), el momento climatológico, la susceptibilidad del material a la enfermedad, además del modo y mecanismo de acción de los productos, lo cual es fundamental para lograr un buen control de la enfermedad, evitar la generación de resistencia en el patógeno, la presencia de trazas de plaguicidas en la fruta y la contaminación del ambiente. También es importante considerar la calibración de la fumigadora, el desempeño del operario y seguir las recomendaciones de la ficha técnica del producto que se va a aplicar (Arroyave y Salazar s. f.; Tamayo y Peláez 2000; Forero et al. 2002; Ávila et al. 2003; González et al. 2003; Tamayo 2003; Forero 2007; Marulanda et al. 2011; Múnera et al. 2012; Saldarriaga et al. 2012; Betancourt et al. 2014; Mesa et al. 2014; PLM 2016). 
Tabla 1. Niveles de severidad de antracnosis y acciones para el manejo integrado

\section{Severidad de antracnosis en tallos}

\begin{tabular}{|c|c|c|}
\hline Baja: menor del $2 \%$ & Media: entre el 2 y el $10 \%$ & Alta: mayor del $10 \%$ \\
\hline $\begin{array}{l}\text { Acciones: } \\
\text { 1. Mantener el monitoreo } \\
\text { semanal (en temporadas } \\
\text { húmedas) o quincenal (en } \\
\text { épocas secas). } \\
\text { 2. Reforzar las labores } \\
\text { culturales, en especial } \\
\text { podas (aireación, } \\
\text { sanitarias, ramas que } \\
\text { ya produjeron), plateo y } \\
\text { desyerbas. Para el manejo } \\
\text { de esta enfermedad, es } \\
\text { importante la denominada } \\
\text { poda de realce, consistente } \\
\text { en remover el follaje en } \\
\text { el tercio bajo de la planta } \\
\text { para mantener los tallos } \\
\text { con buena circulación } \\
\text { de aire, disminuir la } \\
\text { humedad y desfavorecer } \\
\text { los procesos de infección } \\
\text { del hongo y desarrollo } \\
\text { de la enfermedad. }\end{array}$ & $\begin{array}{l}\text { Acciones: } \\
\text { 1. Intensificar las labores } \\
\text { culturales (podas, remoción } \\
\text { y destrucción de restos de } \\
\text { podas afectados por enfer- } \\
\text { medades, plateo, control de } \\
\text { malezas). } \\
\text { 2. Revisar y ajustar la } \\
\text { fertilización según el } \\
\text { análisis químico del suelo } \\
\text { y los requerimientos del } \\
\text { cultivo (Franco y Giraldo } \\
\text { 2002; Castellanos y Botero } \\
\text { 2003; Díaz et al. 2009). } \\
\text { 3. Revisar y ajustar } \\
\text { distancias de siembra } \\
\text { (de ser necesario hacer } \\
\text { entresacas) para disminuir } \\
\text { humedad dentro de la } \\
\text { plantación. } \\
\text { 4. Complementar las labores } \\
\text { culturales con aspersión de } \\
\text { fungicidas en rotación. } \\
\text { 5. Monitoreo de tallos para } \\
\text { verificar la eficiencia de } \\
\text { las medidas sanitarias, en } \\
\text { especial la protección en los } \\
\text { tallos nuevos. }\end{array}$ & $\begin{array}{l}\text { Acciones: } \\
\text { 1. Realizar poda severa } \\
\text { de los tallos afectados } \\
\text { y, si la incidencia es } \\
\text { mayor del } 50 \% \text { (es } \\
\text { decir, más del } 50 \% \text { de } \\
\text { los tallos con severidad } \\
\text { mayor del } 10 \% \text { ), } \\
\text { considerar la realización } \\
\text { de una poda severa a } \\
\text { ras del suelo para } \\
\text { renovar el cultivo. }\end{array}$ \\
\hline
\end{tabular}




\section{Mildeo velloso, peronospora, tusa}

Esta enfermedad es ocasionada por especies patógenas del reino Stramenopila (Chromista) (Castaño 2015): Peronospora rubi Rabenh. (Buriticá 1999), Peronospora Corda (Tamayo 2003), Peronospora potentillae Bary y Peronospora sparsa Berk (Betancourt et al. 2014).

\section{Síntomas}

El mildeo velloso afecta tallos, peciolos, pedúnculos, botones florales y frutos. Los tallos y pedúnculos enfermos presentan coloraciones moradas (figura $4 \mathrm{a}$ ), sobre las que ocasionalmente aparecen lesiones blancas (figura $4 \mathrm{~b}$ ), y sobre estas puede aparecer una vellosidad de color gris claro, que corresponde a la esporulación del patógeno (Saldarriaga y Bernal 2000; Tamayo 2003). En los botones florales, se presentan lesiones de color café claro a negro, que progresan hasta cubrir completamente la estructura y que en general están acompañadas de lesiones con tonalidades moradas en peciolos y pedúnculos que acompañan la estructura floral; sobre las lesiones puede aparecer también la esporulación del patógeno (figura 4c). En los frutos afectados, se observa desarrollo irregular de las drupas, maduración desuniforme y pérdida de brillo, lo cual demerita el producto para la comercialización (Saldarriaga y Bernal 2000). Los frutos verdes detienen el crecimiento, sufren malformaciones y se maduran prematuramente (figura $4 \mathrm{~d}$ ). En temporadas húmedas, el patógeno esporula sobre la superficie de los órganos afectados (figura 4e).

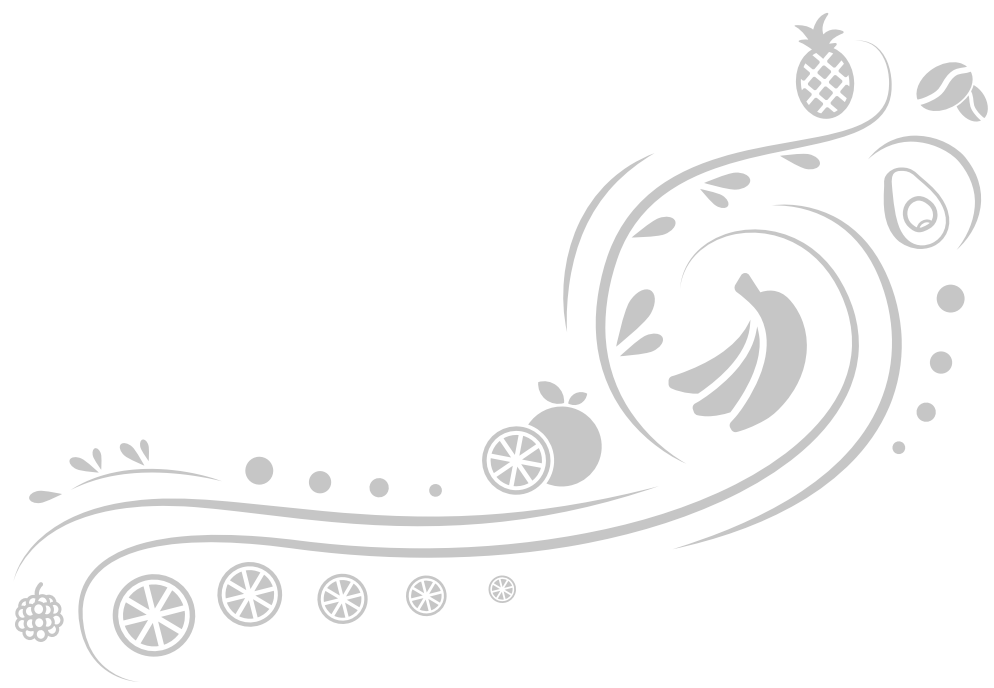



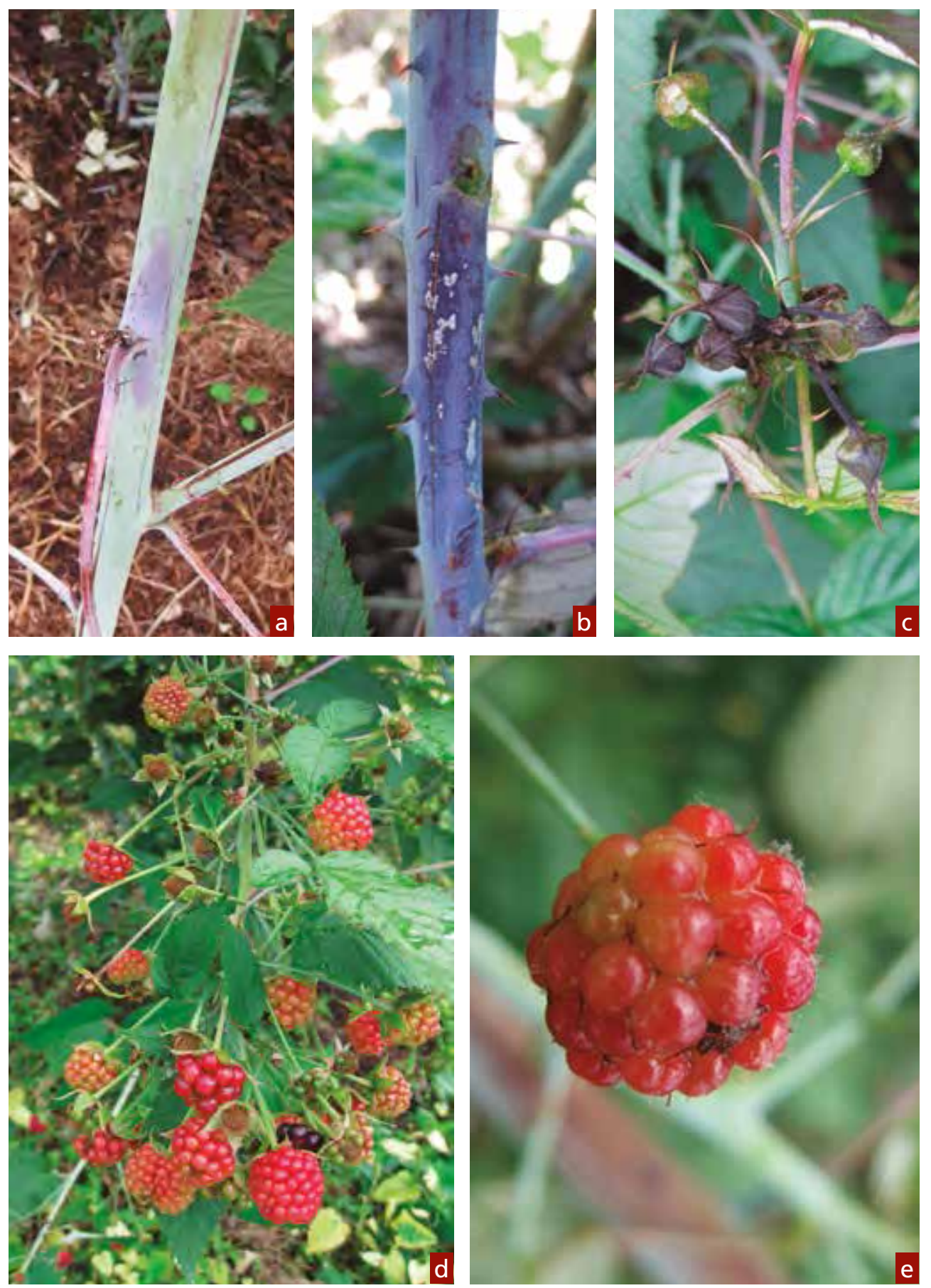

Figura 4. Síntomas de mildeo velloso en diferentes órganos de la planta de mora. a. Síntoma inicial en tallos; b. Manchas moradas y esporulación del patógeno en el tallo; c. Necrosis de los botones florales, acompañada de lesiones y esporulación del patógeno en peciolo y botón floral; d. Malformación, maduración prematura de los frutos y llenado irregular de las drupas; e. Esporulación del patógeno sobre el fruto. 


\section{Monitoreo de la enfermedad}

Esta enfermedad se ve favorecida por condiciones de humedad relativa alta, cultivos enmalezados y sin podas (Betancourt et al. 2014; Mesa et al. 2014).

Para la cuantificación de la enfermedad, se monitorean los tallos y se halla la incidencia (I) y la severidad (S), lo cual se realiza de la siguiente forma: para estimar la incidencia, en cada una de las plantas seleccionadas (teniendo en cuenta los criterios ilustrados en la figura 2), se cuentan los tallos principales sanos y enfermos por mildeo velloso y se calcula la incidencia (I) mediante la observación de lesiones de este patógeno en el tercio medio e inferior de ellos y se aplica la ecuación 1 (anexo). Para el cálculo de la severidad, en $20 \mathrm{~cm}$ del tercio bajo de los tallos afectados de las plantas muestreadas, se realiza la cuantificación, con el uso de un diagrama (figura 5), que considera cinco niveles de severidad, definidos por el porcentaje de área de tejido de tallo afectado, así: nivel 1: $1 \%$ de tejido afectado; nivel 2: $5 \%$ de tejido afectado; nivel 3: $10 \%$ de tejido afectado; nivel 4: $25 \%$ de tejido afectado; y nivel 5: $50 \%$ o más de tejido afectado (Castaño 2002; Botero et al. 2003; Múnera et al. 2012; Saldarriaga 2012; Díaz et al. 2013).

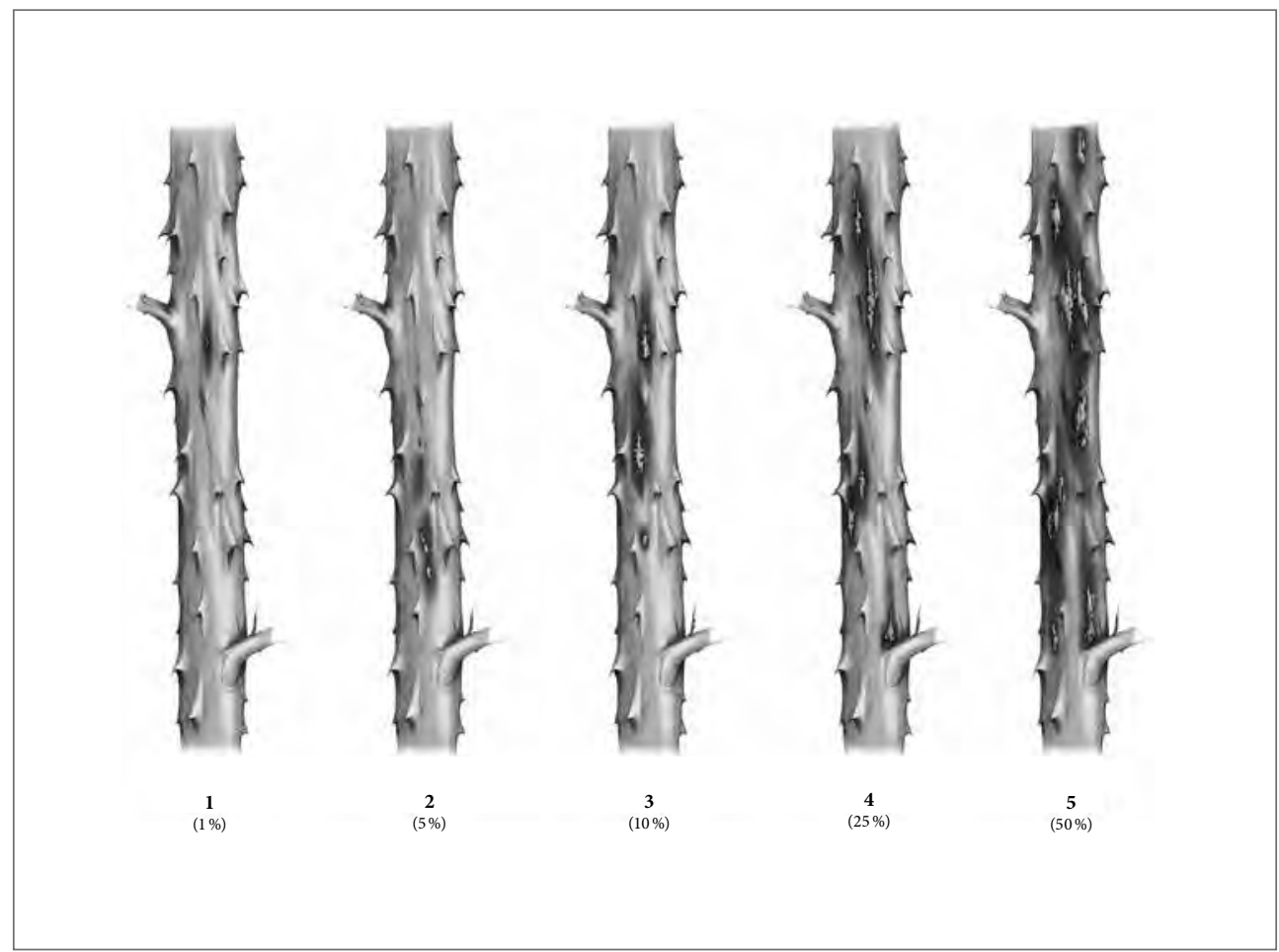

Figura 5. Niveles de severidad de mildeo velloso en tallos de mora. 
La información tomada en campo se procesa para obtener los valores medios de severidad de la enfermedad (anexo) en el cultivo en el momento de realizar el monitoreo $y$, de acuerdo con estos, se consideran las medidas por emplear para el manejo de la enfermedad. Se considera un nivel bajo de severidad cuando es menor del $5 \%$, medio entre el $5 \%$ y el $25 \%$ y alto cuando es mayor del $25 \%$.

En los frutos, la incidencia (If) toma importancia en especial para la valoración de las pérdidas. Esta variable se estima en las plantas seleccionadas con el conteo en cuatro racimos por planta (orientados hacia al norte, sur, oriente y occidente). En cada racimo, se cuenta el total de frutos y, en estos, el número de ellos que presenta síntomas de mildeo velloso; la incidencia por racimo se estima, mediante la ecuación 2.

$\begin{aligned} & \text { Porcentaje de incidencia de } \\ & \text { mildeo velloso en frutos (If) }\end{aligned}=\frac{\text { Número de frutos afectados en el racimo }}{\text { Número total de frutos del racimo }} \cdot 100$

Ecuación 2

Se promedian los valores If de los cuatro racimos para hallar la incidencia por planta y luego se calcula el valor promedio para el total de las plantas evaluadas (anexo).

\section{Manejo integrado del mildeo velloso}

Se recomienda la realización oportuna de podas sanitarias, de aireación y de ramas que ya dieron frutos, control de malezas y fertilización, además de tener en cuenta el momento climatológico, la fenología del cultivo y los niveles de la enfermedad. Cuando la severidad en tallos supera el $5 \%$ o más, se deben complementar las acciones de manejo agronómico del cultivo con la aplicación de los fungicidas a base de mandipropamida, azoxystrobin, propineb + fluopicolide, fosetil aluminio, ácido fosforoso, dimetomorf, cymoxanil + propamocarb, metalaxyl, cymoxanil, y productos con ingredientes activos a base de cobre. La selección del fungicida por aplicar debe considerar el nivel de enfermedad que se esté presentando en el cultivo (tabla 2), las instrucciones de la ficha técnica de los productos, el modo y el mecanismo de acción y la rotación de los productos. También es fundamental la calibración del equipo para fumigación y el desempeño del operario que la ejecutará (Arroyave y Salazar s.f.; Tamayo y Peláez 2000; Peláez et al. 2000; Tamayo 2003; Múnera et al. 2012; Saldarriaga 2012; Díaz et al. 2013; Betancourt et al. 2014; Mesa et al. 2014; PLM 2016). 
Tabla 2. Niveles de severidad de mildeo velloso y acciones para el manejo integrado

\section{Severidad de mildeo velloso en tallos}

Baja: menor del $5 \%$

Acciones:

1. Mantener el monitoreo semanal (en temporadas húmedas) o quincenal (en épocas secas).

2. Reforzar las labores culturales, en especial podas (aireación, sanitarias, ramas que ya produjeron), plateo y desyerbas. Para el manejo de esta enfermedad, es importante mantener los tallos con buena circulación de aire, disminuir la humedad dentro de la plantación para desfavorecer el desarrollo e incremento de la enfermedad.
Media: entre el 5 y el $25 \%$

Acciones:

1. Intensificar las labores culturales (podas, remoción y destrucción de restos de podas afectados por enfermedades, plateo, control de malezas).

2. Revisar y ajustar la fertilización según el análisis químico del suelo y los requerimientos del cultivo (Franco y Giraldo 2002; Castellanos y Botero 2003; Díaz et al. 2009).

3. Revisar y ajustar distancias de siembra (de ser necesario hacer entresacas) para disminuir humedad dentro de la plantación.
4. Complementar las labores culturales con aspersión de fungicidas en rotación.
5. Monitoreo de tallos para verificar la eficiencia de las medidas sanitarias, en especial la protección en los tallos nuevos.

Alta: mayor del $25 \%$

Acciones:

1. Realizar poda severa de los tallos afectados, aplicar las labores culturales y el control químico oportunamente, si la incidencia es mayor del $50 \%$ (es decir, más del $50 \%$ de los tallos presenta severidad mayor del $25 \%$ ), considerar la realización de una poda severa a ras del suelo para renovar el cultivo.

Fuente: Elaboración propia

La cuantificación de la incidencia en frutos brinda la posibilidad de determinar el punto de equilibrio y el momento en el que se empiezan a tener pérdidas, según variables económicas y agronómicas y sirve para reforzar las medidas de manejo o tomar decisiones. En la tabla 3 se presentan niveles de incidencia que generan alertas respecto del riesgo de obtener pérdidas en la producción, considerando el ejercicio económico contemplado en el anexo. 
Tabla 3. Incidencia de mildeo velloso en frutos, significado y consideraciones para el manejo integrado de la enfermedad

\section{Incidencia de mildeo velloso en frutos}

\begin{tabular}{|c|c|c|}
\hline Baja: menor del $25 \%$ & Media: entre el 25 y el $29 \%$ & Alta: mayor del $29 \%$ \\
\hline $\begin{array}{l}\text { A medida que decrece } \\
\text { la incidencia, se } \\
\text { incrementa el } \\
\text { margen de ganancia. } \\
\text { Sin embargo, la } \\
\text { presencia de la } \\
\text { enfermedad en los } \\
\text { frutos, así sea baja y } \\
\text { no cause pérdida } \\
\text { económica, genera } \\
\text { alerta para la toma } \\
\text { de acciones de } \\
\text { manejo integrado } \\
\text { en el cultivo. } \\
\text { Acciones: } \\
\text { 1. Considerar los } \\
\text { valores de incidencia } \\
\text { y los niveles de } \\
\text { severidad en tallos y } \\
\text { aplicar las acciones } \\
\text { contempladas en la } \\
\text { tabla } 2 \text { para evitar } \\
\text { que la enfermedad } \\
\text { continúe el progreso. }\end{array}$ & $\begin{array}{l}\text { Indica que aún no se tienen } \\
\text { pérdidas económicas, pero } \\
\text { se está aproximando al } \\
\text { nivel de riesgo del } 29 \% \text { (valor } \\
\text { correspondiente al punto de } \\
\text { equilibrio en el que no } \\
\text { hay pérdida ni ganancia } \\
\text { económica). En este intervalo, } \\
\text { una incidencia del } 25 \% \text { indica } \\
\text { una ganancia alrededor del } \\
\text { 5\%, a pesar de la afectación } \\
\text { de los frutos (asumiendo } \\
\text { rechazo de los frutos } \\
\text { enfermos). } \\
\text { Acciones: } \\
\text { 1. Considerar los valores de } \\
\text { incidencia y severidad en tallos y, } \\
\text { de acuerdo con estos, aplicar las } \\
\text { medidas (acciones) de } \\
\text { manejo de la enfermedad. } \\
\text { 2. Intensificar las podas } \\
\text { sanitarias de estructuras } \\
\text { reproductivas (botones florales, } \\
\text { frutos) afectadas, con remoción } \\
\text { y destrucción de los restos de la } \\
\text { poda fuera del cultivo. Comple- } \\
\text { mentar la acción con aspersión de } \\
\text { fungicidas en rotación. } \\
\text { 3. Monitoreo estricto de } \\
\text { tallos y racimos para verificar la } \\
\text { eficiencia de las medidas } \\
\text { sanitarias, en especial la } \\
\text { protección en los tallos y } \\
\text { frutos nuevos. }\end{array}$ & $\begin{array}{l}\text { A partir de este valor } \\
\text { se obtienen pérdidas } \\
\text { económicas que afectan } \\
\text { la rentabilidad del } \\
\text { cultivo (anexo), } \\
\text { asumiendo que los } \\
\text { frutos enfermos } \\
\text { sean rechazados. } \\
\text { Acciones: } \\
\text { 1. Realizar poda severa de } \\
\text { tallos, ramas y } \\
\text { racimos afectados, } \\
\text { considerar los valores de } \\
\text { incidencia y severidad en } \\
\text { tallos, complementar con } \\
\text { aspersión de } \\
\text { fungicidas y demás } \\
\text { acciones recomendadas } \\
\text { para el manejo de la } \\
\text { enfermedad. Si más del } \\
50 \% \text { de los tallos presenta } \\
\text { severidad mayor del } 25 \% \\
\text { y la incidencia en frutos } \\
\text { supera el } 29 \% \text {, realizar } \\
\text { poda severa a ras del } \\
\text { suelo para renovar } \\
\text { el cultivo. }\end{array}$ \\
\hline
\end{tabular}




\section{Mildeo polvoso, cenicilla, crespera}

Esta enfermedad es ocasionada por el hongo Oidium Link (Tamayo 2003).

\section{Síntomas}

El mildeo polvoso se manifiesta principalmente en las hojas jóvenes, en las que produce deformación (encrespamiento), asociada a la presencia de áreas cloróticas irregulares y difusas que se observan en la superficie de la lámina foliar (figura 6a). Ocasionalmente, en temporadas calurosas o bajo condiciones de invernadero, las hojas se cubren de un polvillo blanco, que corresponde al crecimiento y la esporulación del hongo (figura 6b). La enfermedad también afecta los botones florales y frutos en diferentes estados de desarrollo. Los botones florales alteran su desarrollo y presentan un polvillo blanco, que crece sobre su superficie (figura 6c). Los frutos enfermos retrasan el crecimiento, sufren malformación y exhiben la esporulación blanquecina del hongo (figura 6d). Las estructuras florales y los frutos se necrosan y sobre ellos se aprecia la esporulación del patógeno (figura 6e). En afecciones tardías, los frutos que se alcanzan a formar pueden presentar el crecimiento del hongo (figura 6f) (Saldarriaga y Bernal 2000; Tamayo 2003). Según Betancourt et al. (2014), el hongo ocasiona disminución del crecimiento y la fotosíntesis e incremento de la respiración de la planta. En ocasiones, las ramas afectadas se adelgazan y toman apariencia de látigos (Franco y Giraldo 2002).

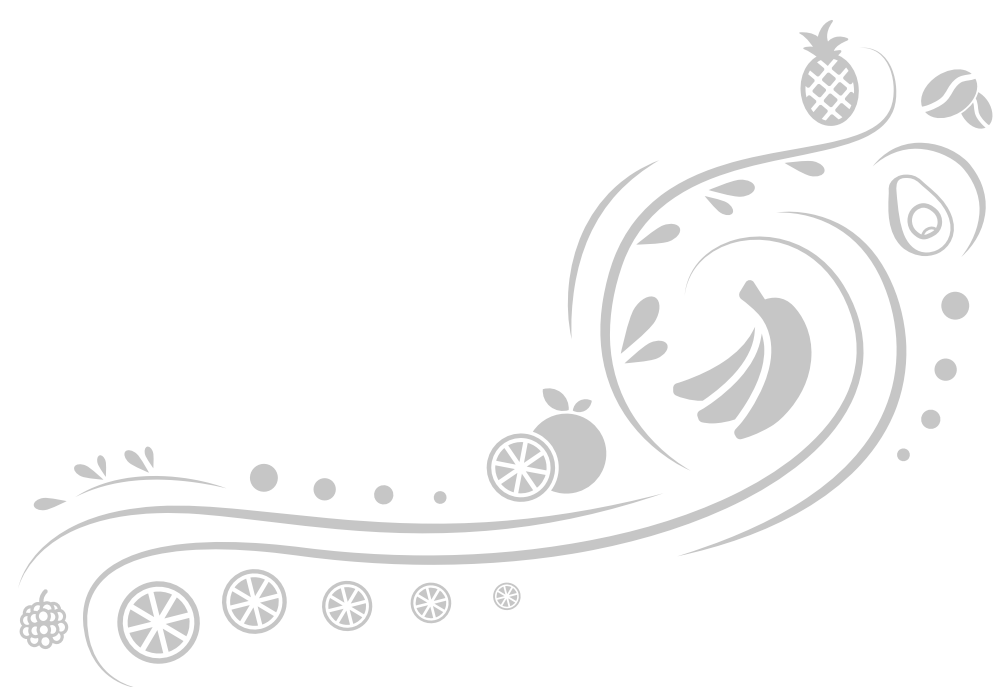



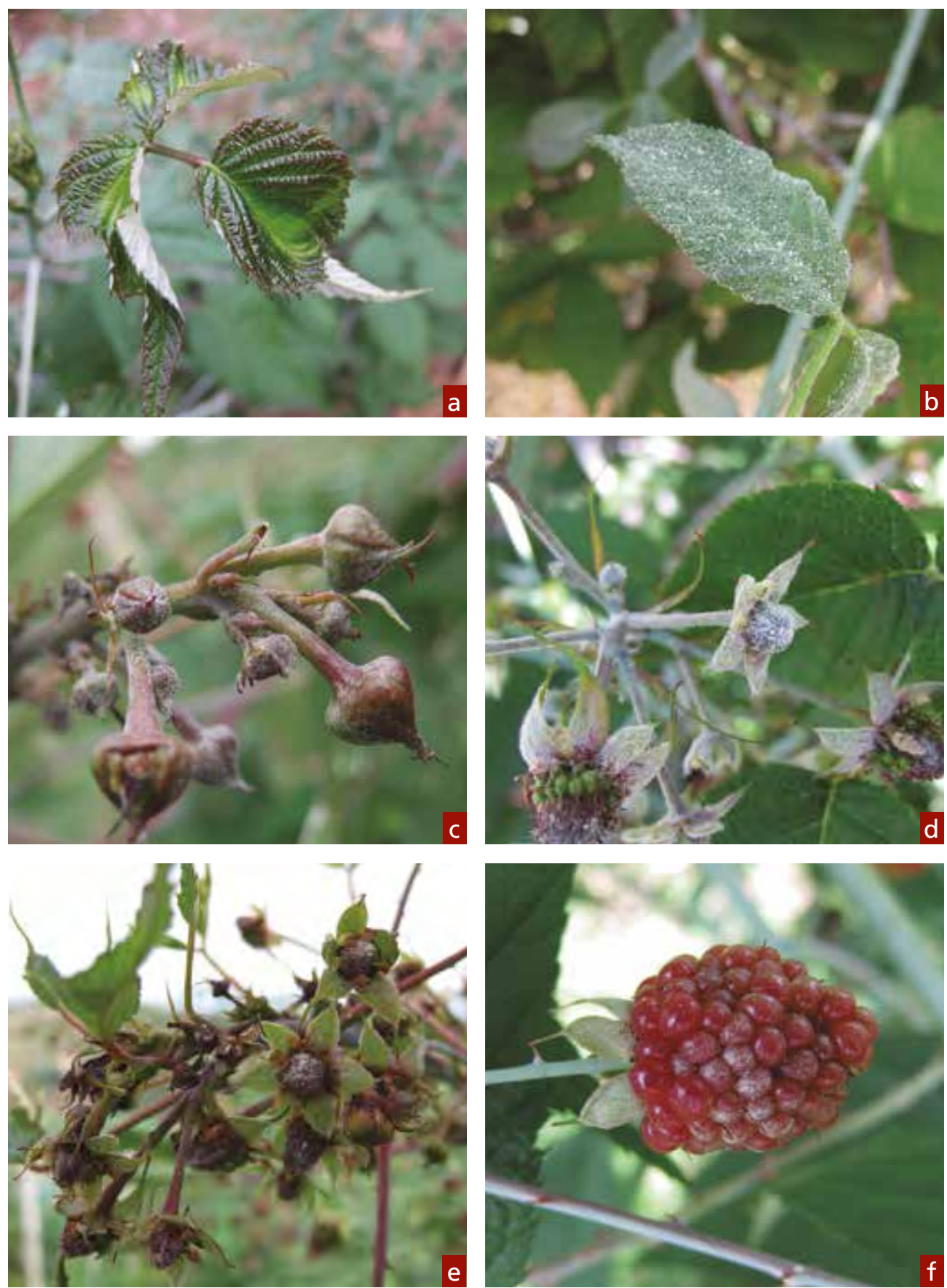

Figura 6. Síntomas de mildeo polvoso en diferentes órganos de la planta de mora. a. Síntoma de encrespamiento y zonas cloróticas en hojas; b. Esporulación del hongo en la lámina foliar; c. Esporulación del patógeno sobre botones florales; d. Malformación de frutos y esporulación del hongo en la superficie de los tejidos ; e. Necrosamiento y malformación de estructuras reproductivas con esporulación del hongo; f. Esporulación del hongo sobre fruto maduro. 


\section{Monitoreo de la enfermedad}

El mildeo polvoso se favorece por temporadas secas y calurosas, almácigos bajo invernadero, plantas con deficiencias de azufre y hierro (Tamayo 2003; Betancourt et al. 2014). El cultivo se debe revisar para detectar oportunamente los síntomas de la enfermedad en las hojas y otras estructuras. La afección es más frecuente en hojas donde presenta incidencias y severidades variables; en este caso, se realiza la evaluación en las hojas.

En las hojas, la incidencia (Ih) se estima en las plantas seleccionadas (teniendo en cuenta los criterios ilustrados en la figura 2) con el conteo de hojas en cuatro ramas por planta (orientadas hacia al norte, sur, oriente y occidente). En cada rama, se cuenta el total de hojas y, de estas, el número de ellas que presentan síntomas de mildeo polvoso; la incidencia por rama se estima mediante la ecuación 3.

$\begin{aligned} & \text { Porcentaje de incidencia de } \\ & \text { mildeo polvoso en hojas }(\mathrm{Ih})\end{aligned}=\frac{\text { Número de hojas afectadas en la rama }}{\text { Número total de hojas de la rama }} \cdot 100$

Ecuación 3

Se promedian los valores (Ih) de las cuatro ramas para hallar la incidencia por planta y luego se calcula el valor promedio para las plantas evaluadas (anexo).

Para cuantificar la severidad (S) del mildeo polvoso, en las mismas cuatro ramas en las que se evaluó la incidencia, se visualizan las primeras seis hojas de cada rama a partir de la hoja más joven totalmente expandida (una hoja está compuesta por tres foliolos; con uno de ellos que esté afectado, se considera que la hoja está enferma) y se comparan con el diagrama (figura 7), que considera cinco niveles, definidos por el porcentaje de área de tejido foliar afectado por la enfermedad, así: nivel 1: 1\% de tejido afectado; nivel 2: $5 \%$ de tejido afectado; nivel 3: $10 \%$ de tejido afectado; nivel 4: $25 \%$ de tejido afectado; y nivel 5: $50 \%$ o más de tejido afectado. 


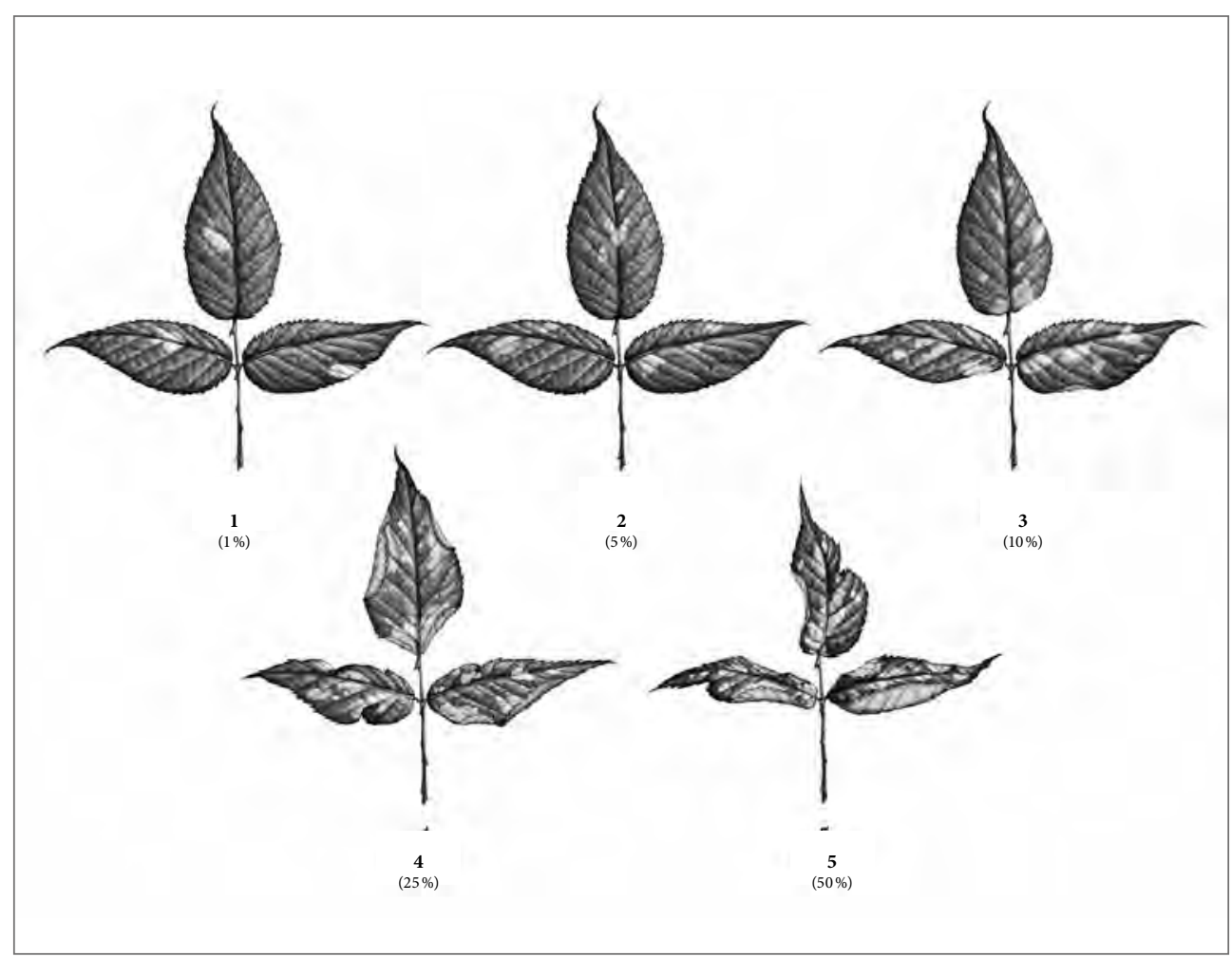

Figura 7. Niveles de severidad de mildeo polvoso en hojas de mora. Fuente: Elaboración propia

La información se procesa para obtener los valores medios de severidad de la enfermedad por rama y planta y, de acuerdo con esto, se definen las medidas para el manejo de la plantación (anexo). Se considera un nivel bajo de severidad cuando es menor del $5 \%$, medio entre el $5 \%$ y el $20 \%$ y alto cuando es mayor del $20 \%$. Estos niveles deben ser monitoreados para tomar medidas sanitarias y evitar que la enfermedad progrese y afecte las estructuras reproductivas.

La evaluación de incidencia en racimos (con estructuras reproductivas compuestas por botones florales, flores y frutos) tiene importancia cuando la enfermedad, por algún motivo, ha avanzado hasta llegar a afectar estos órganos; en este caso, sirve para estimar pérdidas potenciales. Para la cuantificación, se seleccionan cuatro racimos por planta (orientados hacia al norte, sur, oriente y occidente), se cuentan las estructuras reproductivas totales (botones florales, flores y frutos) y las estructuras afectadas por mildeo polvoso y se aplica la ecuación 4 . 


$\begin{gathered}\text { Porcentaje de incidencia de } \\ \text { mildeo polvoso en estructuras }\end{gathered}=$
reproductivas $(\mathrm{Ie})$$\quad \begin{gathered}\begin{array}{c}\text { Número de estructuras } \\ \text { afectadas en el racimo }\end{array} \\ \begin{array}{c}\text { Número total de estructuras } \\ \text { del racimo }\end{array}\end{gathered}$

Ecuación 4

Se promedian los valores (Ie) de los cuatro racimos para hallar la incidencia por planta y, luego, se calcula el valor promedio para el total de las plantas evaluadas (anexo). Se considera un nivel bajo de incidencia cuando es menor del $25 \%$, medio entre el $25 \%$ y el $29 \%$ y alto cuando es mayor del $29 \%$, teniendo en cuenta el ejercicio económico planteado en el anexo.

\section{Manejo integrado de mildeo polvoso, cenicilla, crespera}

Esta enfermedad es prevalente en temporadas secas y calurosas. Para el manejo integrado, es indispensable la realización oportuna de las podas sanitarias y de mantenimiento del cultivo y la aplicación complementaria de fungicidas a base de azufre en rotación con productos con ingredientes activos, como hexaconazol, bupirimato, difenoconazol y sulfato cuprocálcico. Se sugiere iniciar el programa de aplicación de fungicidas cuando la severidad en ramas (calculada a partir de la evaluación en hojas) sea igual o mayor al $5 \%$. Se debe tener en cuenta, además, el momento climatológico, los modos y mecanismos de acción de los productos, las indicaciones de la ficha técnica de los fungicidas y la calibración del equipo de fumigación (Arroyave y Salazar s. f.; Tamayo 2003; Múnera et al. 2012; Saldarriaga 2012; Betancourt et al. 2014; Mesa et al. 2014; PLM 2016). Un manejo deficiente de la enfermedad en las ramas puede ocasionar que esta progrese y llegue a afectar las estructuras reproductivas, lo cual ocasiona pérdidas de frutos que no se podrán comercializar. La tabla 4 presenta sugerencias para el manejo integrado de la enfermedad de acuerdo con la severidad. 
Tabla 4. Niveles de severidad de mildeo polvoso en ramas y acciones sugeridas para el manejo

\section{Severidad de mildeo polvoso en ramas}

Baja: menor del $5 \%$

Acciones:

1. Mantener

el monitoreo

semanal (en

temporada seca)

y quincenal (en

periodos con lluvias

frecuentes).

\section{Mantener las}

labores culturales, en especial podas, destrucción de restos afectados por enfermedades, plateos y desyerbas.

\section{Revisar y ajustar el programa de fertilización con especial atención a los nutrientes azufre y hierro.}

Media: entre el 5 y el $20 \%$

Acciones:

1. Intensificar las labores culturales (poda semanal con remoción y destrucción de restos de podas afectados por enfermedades, plateo, control de malezas).

2. Fertilizar según el análisis químico del suelo y los requerimientos del cultivo.

\section{Complementar las} labores culturales con aspersión de fungicidas en rotación.

\section{Monitoreo de ramas} para verificar la eficiencia de las medidas sanitarias, en la protección de las hojas y estructuras reproductivas nuevas.
Alta: mayor del $20 \%$
1. Realizar poda severa de ramas enfermas y estructuras reproductivas (si se observan afectadas). Implementar un programa de protección del nuevo follaje con aplicación de fungicidas y monitoreo periódico de la enfermedad (incidencia y severidad), para verificar la eficiencia de las prácticas y decidir la forma de continuar el manejo. En caso de no lograrse un manejo satisfactorio de la enfermedad y persistir niveles altos de incidencia y severidad en ramas y afectación de estructuras reproductivas, considerar renovación del cultivo (poda a ras de suelo) o reubicación del cultivo en otro lote de la finca con condiciones ambientales desfavorables a la enfermedad. 


\section{Moho gris, botrytis, pudrición del fruto}

Esta enfermedad es ocasionada por el hongo Botrytis cinerea Pers. ex. Fr. (Tamayo 2003; Betancourt et al. 2014).

\section{Síntomas}

El moho gris es una enfermedad importante durante la etapa de producción y poscosecha; el hongo infecta los botones florales desde su apertura y se manifiesta en la fructificación y maduración, donde ocasiona necrosis y momificación de los frutos (Forero 2007). En presencia de humedad, los frutos afectados exhiben crecimiento del hongo de aspecto afelpado de color grisáceo o verde oliva (figuras $8 \mathrm{a}, 8 \mathrm{~b}$ y 8c). Los frutos en proceso de maduración presentan pudrición húmeda generalizada, con posterior crecimiento y esporulación del hongo (figuras $8 \mathrm{a}$ y 8c). Los frutos se secan (figura 8d) y se momifican adheridos al racimo (Saldarriaga y Bernal 2000; Tamayo 2009). El hongo ocasionalmente puede afectar hojas, flores y pedúnculos (Franco y Giraldo 2002; Zapata et al. 2013).

\section{Monitoreo de la enfermedad}

La enfermedad se favorece por condiciones de humedad relativa alta, lluvias continuas y temperaturas bajas, cultivos enmalezados, podas deficientes y sobremaduración de los frutos en la planta (Botero et al. 2003; Betancourt et al. 2014). La cuantificación de la enfermedad se realiza en los frutos, dado que este es el órgano donde se manifiesta con mayor prevalencia. En cada planta seleccionada (teniendo en cuenta los aspectos descritos e ilustrados en la figura 2), se escogen cuatro racimos (orientados al norte, sur, oriente, occidente) que tengan al menos el $50 \%$ de los frutos en grado 4 de maduración o superior (Icontec 1997; Castellanos y Botero 2003). En cada racimo, se realiza el conteo de frutos totales y frutos con síntomas de moho gris y se estima la incidencia (If) mediante el uso de la ecuación 5.

$$
\begin{gathered}
\text { Porcentaje de incidencia } \\
\text { de moho gris en frutos (If) }
\end{gathered}=\frac{\begin{array}{c}
\text { Número de frutos } \\
\text { afectados en el racimo }
\end{array}}{\text { Número total de frutos del racimo }} \cdot 100
$$

Ecuación 5 

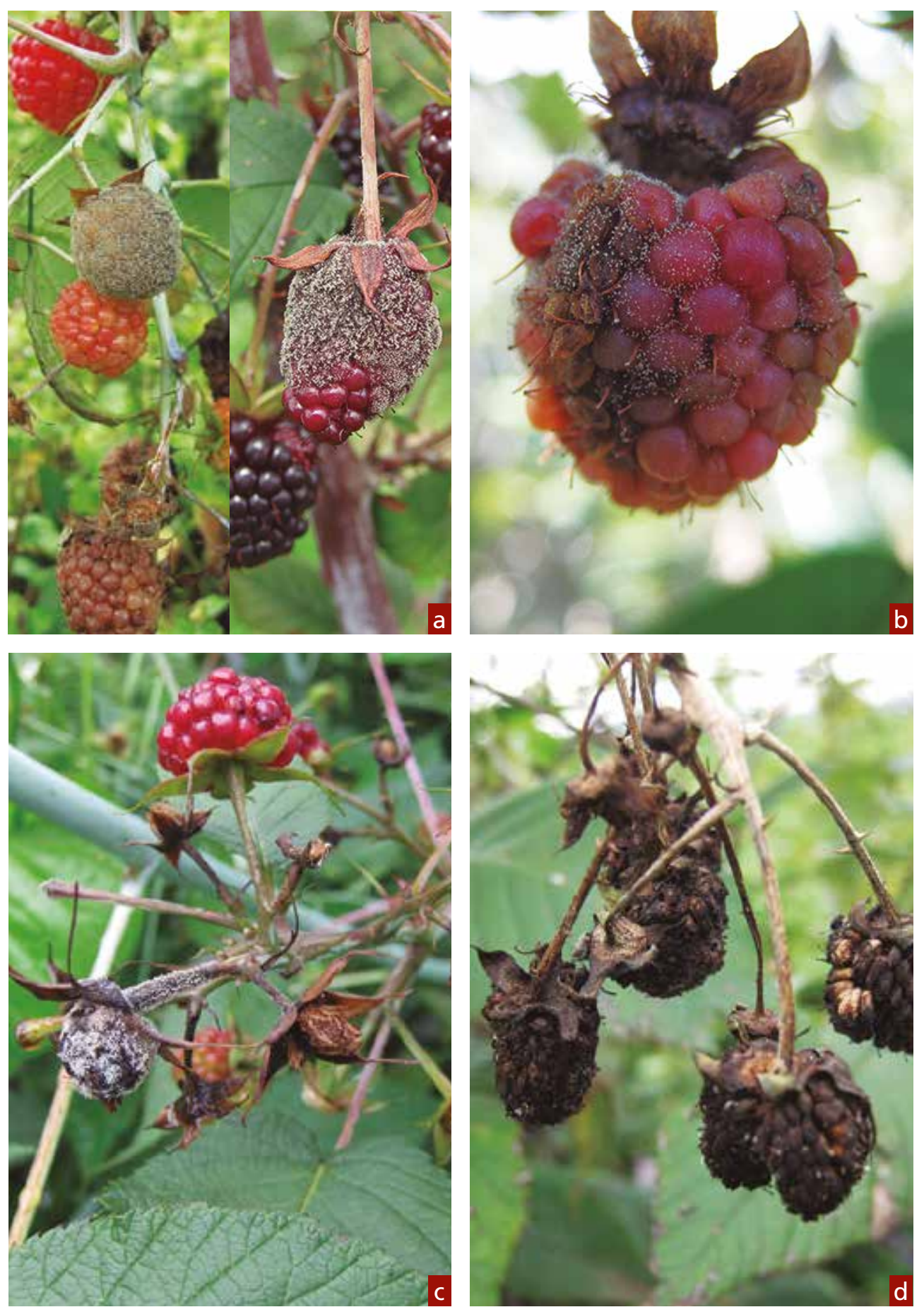

Figura 8. Síntomas de moho gris en frutos de mora. a. Pudrición blanda, crecimiento y esporulación del hongo sobre frutos; b. Crecimiento inicial del hongo en la superficie del fruto; c. Crecimiento y esporulación del hongo en el fruto y en el pedúnculo; d. Necrosis y momificación de los frutos. 
Se promedian los valores (If) de los cuatro racimos para hallar la incidencia por planta y, luego, se calcula el valor promedio para el total de las plantas evaluadas. Cuando la incidencia en frutos presenta un valor del $25 \%$ o más, se deben complementar las labores culturales con aplicación de fungicidas para el manejo de la enfermedad.

\section{Manejo integrado del moho gris}

Es fundamental la realización oportuna de la cosecha con remoción, retirado del lote y destrucción de frutos enfermos, control de malezas, eliminación de ramas enfermas y las que ya produjeron, además de hacer podas de mantenimiento que faciliten la aireación de las plantas para disminuir la humedad dentro de la plantación. En temporadas de alta humedad y, si la incidencia de la enfermedad supera el valor del $25 \%$, se hace necesaria la aplicación de fungicidas a base de iprodione, fenhexamid, procloraz, fenhexamid + tebuconazole, pyrimethanil, dichlofluanid, controladores biológicos a base del hongo Trichoderma, para lo cual se debe diseñar un programa de rotación que tenga en cuenta el modo y los mecanismo de acción de los fungicidas, a fin de evitar la generación de resistencia en el patógeno (Arroyave y Salazar s. f.; Tamayo 2003; Hincapié y Saldarriaga 2009; Hincapié et al. 2010; Hincapié 2010; Múnera et al. 2012; Saldarriaga 2012; Zapata et al. 2013; Betancourt et al. 2014; PLM 2016). En la tabla 5, se presentan sugerencias para el manejo integrado del moho gris según la incidencia de la enfermedad en los frutos.

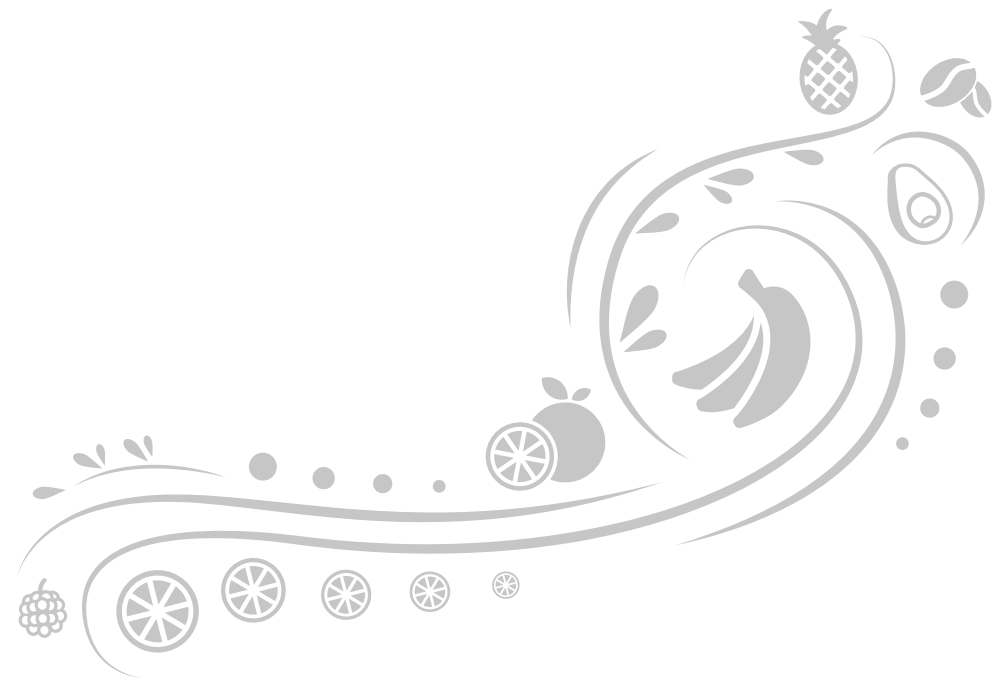


Tabla 5. Incidencia de moho gris en frutos y acciones sugeridas para el manejo

\section{Incidencia de moho gris en frutos}

Baja: menor del $25 \%$

Acciones:

1. Mantener el

monitoreo semanal

en temporada

lluviosa y quincenal

en periodos secos.

\section{Realizar}

oportunamente las labores culturales, en especial podas, destrucción de restos afectados por enfermedades, plateos y desyerbas.

\section{Realizar cosecha oportuna y no dejar sobremadurar los frutos en la planta.}

4. Remover y retirar
del cultivo los
frutos afectados y
destruirlos fuera
de la plantación.

$$
\text { Media: entre el } 25 \text { y el } 29 \%
$$

Acciones:

1. Intensificar las labores culturales (poda semanal con remoción y destrucción de frutos enfermos, plateo y control de malezas).

\section{Revisar y ajustar las distancias} de siembra (entresaca de plantas) para favorecer aireación dentro de la plantación.

\section{Fertilizar según el análisis} químico del suelo y los requerimientos del cultivo.

\section{Complementar las labores culturales con aspersión de fungicidas en rotación para el control de la enfermedad.}

5. Mantener el monitoreo de la enfermedad en frutos; además revisar hojas e inflorescencias, para verificar la eficiencia de las medidas sanitarias.
Alta: mayor del 29\%

Acciones:

1. Realizar poda severa de estructuras reproductivas (racimos afectados), sacarlos y destruirlos fuera del cultivo.

2. Si a pesar de realizar labores culturales y aplicación de fungicidas se continúa con incidencia alta, considerar la realización de una poda severa a ras del suelo para renovar el cultivo. 
En general, cuando se realiza el monitoreo de las enfermedades en campo, los datos obtenidos de estas se consignan en un formato o en un aplicativo digital que permita el inmediato procesamiento para la obtención de los valores de incidencia y severidad. La información obtenida, aunada al conocimiento de los aspectos biológicos de los patógenos y las enfermedades, además de las condiciones ambientales en que se desarrolla el cultivo, sirven de fundamento para la toma de decisiones de manejo integrado, orientan en la selección de productos fungicidas y la estrategia de uso de estos. A manera de ejemplo, en el caso de tener unos niveles medios de antracnosis y mildeo velloso, además de atravesar por una temporada de humedad alta, se seleccionaría para complementar las prácticas culturales el uso de un fungicida sistémico que controle simultáneamente las dos enfermedades, como azoxystrobin, para iniciar el programa de manejo. Tener en cuenta no realizar más de dos aplicaciones consecutivas, a fin de minimizar el riesgo de pérdida de sensibilidad del patógeno al producto, por lo cual se rota con otra molécula que tenga mecanismo de acción diferente.

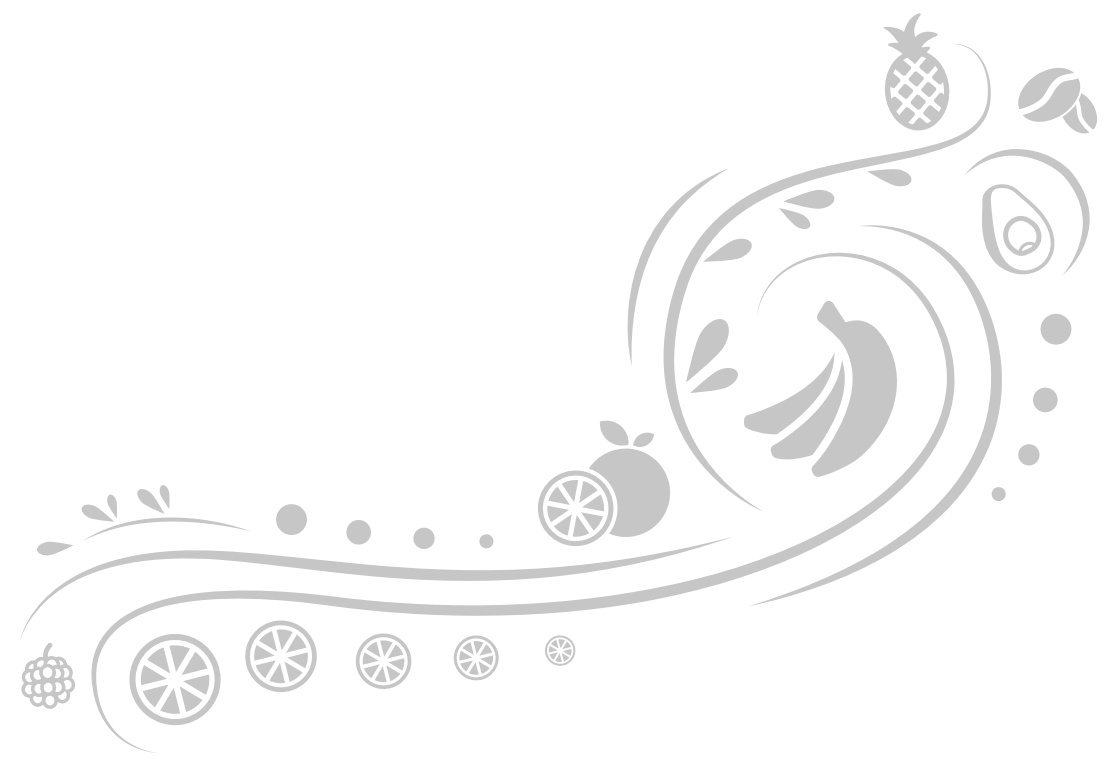





\section{Ejercicio para calcular incidencia y severidad de antracnosis, mildeo velloso, mildeo polvoso y moho gris en plantaciones de mora (Rubus glaucus Benth.)}

Se presenta un ejemplo práctico que detalla la metodología para el cálculo de las incidencias y severidades de las principales enfermedades y la interpretación de los resultados en una plantación hipotética de mora. Este ejercicio contempla el cálculo del punto de equilibrio de la producción en un cultivo comercial de mora para poder determinar las cantidades de fruta que se pueden perder por el ataque de enfermedades sin afectar los rendimientos económicos.

Para estimar pérdidas en mora, se dispone de la información de casos reales de la producción suministrada por Eduardo Zuluaga, productor de mora en Guática (Risaralda).

Una planta produce, en promedio, $1 \mathrm{~kg}$ de mora semanal (promedio de épocas de alta y baja producción). Un kilogramo tiene un promedio de 178 frutos. Cuesta producirlo $\$ 850$ (pesos colombianos de 2016). Un kilogramo de mora se comercializa en promedio en $\$ 1.200$, lo cual constituye un margen de ganancia de $\$ 350$ (representado en 52 frutos). Con esta información, el punto de equilibrio de la producción corresponde a 126 frutos (700 g), semanales por planta, que se deben vender a $\$ 1.200$ por kilogramo. 
Lo anterior indica que se deben cosechar mínimo 126 frutos semanales por planta (punto de equilibrio), los valores superiores son ganancia y los inferiores representan pérdidas económicas en la producción. Para el precio de venta (\$1200 por kilogramo), en el caso que se analiza, la ganancia está representada en 52 frutos equivalentes al $29 \%$, es decir, que la pérdida máxima tolerable en un cultivo con estas características de producción es del $29 \%$ de frutos.

A manera de ejemplo, en un cultivo de mora con una población de 50 plantas, se monitorearon cinco plantas (correspondientes al $10 \%$ de la población) para estimar la incidencia y la severidad de las principales enfermedades y se obtuvieron los reportes de campo que se observan en las tablas 6 y 7 para antracnosis en tallos (incidencia y severidad).

Tabla 6. Formato de campo para el cálculo de la incidencia de antracnosis en tallos de mora

\begin{tabular}{|c|c|c|c|}
\hline Planta & $\begin{array}{c}\text { N. }{ }^{\circ} \text { de tallos por } \\
\text { planta }\end{array}$ & $\begin{array}{c}\text { N. }{ }^{\circ} \text { tallos enfermos } \\
\text { por antracnosis }\end{array}$ & $\begin{array}{c}\text { Incidencia en tallos/ } \\
\text { planta \% }\end{array}$ \\
\hline 1 & 6 & 4 & 66 \\
\hline 2 & 5 & 3 & 60 \\
\hline 4 & 7 & 5 & 71 \\
\hline 5 & 6 & 3 & 50 \\
\hline & Promedio total para el cultivo & 50 \\
\hline
\end{tabular}

Fuente: Elaboración propia

La incidencia se estima en cada una de las plantas a partir de contar los tallos principales sanos y enfermos (sintomáticos) y se aplica la ecuación 1.

$\underset{\text { Porcentaje de incidencia }}{\text { de } \operatorname{antracnosis}(\mathrm{I})}=\frac{\text { Número de tallos afectados por planta }}{\text { Número de tallos observados por planta }} \cdot 100$ 
De esta forma, se obtiene la incidencia por planta y se halla el promedio para el total de plantas muestreadas. Para el ejemplo, la incidencia de antracnosis en tallos es del $59 \%$. Este valor se analiza en conjunto con la severidad, para tener una aproximación al daño potencial.

La severidad se estima en los tallos enfermos con el uso de los diagramas (figura 3), se hace una observación visual de cada uno de los tallos afectados para identificar en qué nivel se encuentra cada uno y se registra el porcentaje del tejido enfermo (1\%, $2 \%, 5 \%, 10 \%)$. Para el caso del ejemplo, los tallos afectados de las plantas seleccionadas para la evaluación presentaron los valores de severidad que se registran en la tabla 7.

Tabla 7. Formato de campo para el cálculo de la severidad de antracnosis en tallos de mora

\begin{tabular}{|c|c|c|c|c|c|c|c|}
\hline \multirow[t]{2}{*}{ Planta } & \multirow{2}{*}{$\begin{array}{c}\text { N. }{ }^{\circ} \text { de } \\
\text { tallos } \\
\text { enfermos }\end{array}$} & Tallo 1 & Tallo 2 & Tallo 3 & Tallo 4 & Tallo 5 & $\begin{array}{c}\text { Severidad } \\
\text { en tallos/ } \\
\text { planta }\end{array}$ \\
\hline & & \multicolumn{5}{|c|}{$\%$ de tejido enfermo } & $\%$ \\
\hline 1 & 4 & 2 & 1 & 5 & 1 & & 2,2 \\
\hline 2 & 3 & 1 & 2 & 1 & & & 1,3 \\
\hline 3 & 5 & 2 & 10 & 5 & 2 & & 4,7 \\
\hline 4 & 3 & 1 & 5 & 2 & & & 2,6 \\
\hline 5 & 2 & 2 & 1 & & & & 1,5 \\
\hline \multicolumn{7}{|c|}{ Promedio total para el cultivo } & 2,4 \\
\hline
\end{tabular}

Fuente: Elaboración propia

La severidad promedio de antracnosis en tallos es del 2,4\%, calificado como una severidad media (entre el $2 \%$ y el $10 \%$ ).

Al analizar los resultados del monitoreo de antracnosis, el 59\% de los tallos de las plantas revisadas y presumiblemente del cultivo presenta los síntomas de la enfermedad y tiene el 2,4\% del tejido afectado por la enfermedad, por lo cual se deben tener en cuenta las acciones contempladas en la tabla 1 y las recomendaciones para el manejo integrado de la enfermedad. 


\section{Mildeo velloso, incidencia y severidad en tallos}

En las mismas plantas del ejemplo anterior, el monitoreo para incidencia de mildeo velloso registró los valores consignados en la tabla 8 .

Tabla 8. Formato de campo para el cálculo de la incidencia de mildeo velloso en tallos de mora

\begin{tabular}{|c|c|c|c|}
\hline Planta & $\begin{array}{c}\text { N.o de tallos } \\
\text { por planta }\end{array}$ & $\begin{array}{c}\text { N.o de tallos enfermos } \\
\text { por mildeo velloso }\end{array}$ & $\begin{array}{c}\text { Incidencia en } \\
\text { tallos/planta \% }\end{array}$ \\
\hline 1 & 6 & 2 & 33 \\
\hline 2 & 5 & 3 & 60 \\
\hline 3 & 7 & 4 & 57 \\
\hline 4 & 6 & 2 & 33 \\
\hline 5 & 4 & 1 & 25 \\
\hline
\end{tabular}

Fuente: Elaboración propia

Al aplicar la ecuación 1, en este caso para los tallos afectados por mildeo velloso, se halló la incidencia por planta evaluada y el promedio total para el cultivo, la cual, para el ejemplo, corresponde al $42 \%$. Este valor se analiza junto con la severidad que estén presentando los tallos y la incidencia en frutos, como criterios para la toma de decisiones de manejo.

Para cuantificar la severidad, se hace uso de los diagramas (figura 5) y, por comparación con cada tallo afectado por mildeo velloso, se registra el porcentaje del tejido enfermo visualizado ( $1 \%, 5 \%, 10 \%, 25 \%, 50 \%)$; los datos se consignan en la tabla 9 .

Tabla 9. Formato de campo para el cálculo de la severidad de mildeo velloso en tallos de mora

\begin{tabular}{|c|c|c|c|c|c|c|c|}
\hline \multirow[t]{2}{*}{ Planta } & \multirow{2}{*}{$\begin{array}{c}\text { N.o de } \\
\text { tallos } \\
\text { enfermos }\end{array}$} & Tallo 1 & Tallo 2 & Tallo 3 & Tallo 4 & Tallo 5 & \multirow{2}{*}{$\begin{array}{c}\text { Severidad en } \\
\text { tallos/planta } \\
\%\end{array}$} \\
\hline & & \multicolumn{5}{|c|}{$\%$ de tejido enfermo } & \\
\hline 1 & 2 & 1 & 5 & & & & 3,0 \\
\hline 2 & 3 & 5 & 1 & 10 & & & 5,3 \\
\hline 3 & 4 & 10 & 1 & 5 & 5 & & 5,2 \\
\hline 4 & 2 & 5 & 1 & & & & 3,0 \\
\hline 5 & 1 & 5 & & & & & 5,0 \\
\hline \multicolumn{7}{|c|}{ Promedio total para el cultivo } & 4,3 \\
\hline
\end{tabular}


Para el ejemplo, la severidad promedio de mildeo velloso en tallos es del 4,3\%, calificada como baja (inferior al $5 \%$ ).

\section{Mildeo velloso, incidencia en frutos}

En campo, en cada uno de los racimos seleccionados por planta, se realiza un conteo de frutos totales por racimo (FTR) y un conteo de los frutos enfermos por racimo (FE), que expresen los síntomas de mildeo velloso y se registran los valores según el formato de la tabla 10; luego, se estima la incidencia de la enfermedad por racimo (Ir) mediante la ecuación 2 .

$\begin{aligned} & \text { Porcentaje de incidencia de } \\ & \text { mildeo velloso en frutos (If) }\end{aligned}=\frac{\text { Número de frutos afectados en el racimo }}{\text { Número total de frutos del racimo }} \cdot 100$

Ecuación 2

Posteriormente, se obtiene la incidencia por planta y el promedio para el cultivo. Para el ejemplo, el conteo realizado en los racimos seleccionados registró los valores presentados en la tabla 10 .

Tabla 10. Formato de campo para registro y cálculo de la incidencia de mildeo velloso en frutos de mora

\begin{tabular}{|c|c|c|c|c|c|c|c|c|c|c|c|c|c|}
\hline \multirow[b]{2}{*}{ Planta } & \multicolumn{3}{|c|}{ Racimo 1} & \multicolumn{3}{|c|}{ Racimo 2} & \multicolumn{3}{|c|}{ Racimo 3} & \multicolumn{3}{|c|}{ Racimo 4} & \multirow{2}{*}{$\begin{array}{c}\text { Incidencia } \\
\text { en frutos/ } \\
\text { planta } \\
\text { (promedio } \\
\text { IR \%) }\end{array}$} \\
\hline & FTR & FE & IR \% & FRT & FE & IR \% & FTR & FE & IR \% & FTR & FE & IR \% & \\
\hline 1 & 43 & 36 & 83 & 56 & 29 & 51 & 34 & 23 & 67 & 52 & 38 & 73 & 68 \\
\hline 2 & 28 & 15 & 53 & 39 & 22 & 56 & 43 & 23 & 53 & 36 & 24 & 66 & 57 \\
\hline 3 & 43 & 15 & 34 & 38 & 20 & 52 & 40 & 22 & 55 & 45 & 30 & 66 & 51 \\
\hline 4 & 38 & 23 & 60 & 46 & 22 & 47 & 45 & 18 & 40 & 50 & 26 & 52 & 50 \\
\hline 5 & 40 & 21 & 52 & 51 & 26 & 50 & 46 & 25 & 54 & 40 & 21 & 52 & 52 \\
\hline \multicolumn{13}{|c|}{ Promedio total para el cultivo } & 55,6 \\
\hline
\end{tabular}

FTR: frutos totales por racimo, FE: enfermos, IR: incidencia por racimo. 
Para el ejemplo, la incidencia promedio de mildeo velloso en frutos es del 55,6\%, valor considerado como alto (supera el $29 \%$ ), y en los tallos se encuentra que el $42 \%$ están afectados, con una severidad de 4,3 considerada baja (inferior al $5 \%$ ). En este caso, el valor de la incidencia en frutos requiere establecer medidas urgentes para disminuir pérdidas y bajar fuente de inóculo que puede infectar los tallos y contribuir al progreso de la enfermedad, por lo que se deben atender las acciones planteadas en las tablas 2 y 3 y las recomendaciones para el manejo integrado de la enfermedad.

\section{Mildeo polvoso, incidencia en hojas}

En las ramas seleccionadas (cuatro ramas jóvenes por planta, orientadas hacia al norte, sur, oriente y occidente), se realiza el conteo de las hojas totales por rama (HTR) y las hojas enfermas (HE), y se estima el porcentaje de incidencia en hojas (Ih) por rama (IR) con el empleo de la ecuación 3.

$\begin{aligned} & \text { Porcentaje de incidencia de } \\ & \text { mildeo polvoso en hojas }(\mathrm{Ih})\end{aligned}=\frac{\text { Número de hojas afectadas en la rama }}{\text { Número total de hojas de la rama }} \cdot 100$

\section{Ecuación 3}

Se promedian los valores (Ih) de las cuatro ramas para hallar la incidencia por planta y luego se calcula el valor promedio para las plantas evaluadas. Para este ejemplo, el conteo de hojas sanas y enfermas en campo dio los resultados presentados en la tabla 11.

Tabla 11. Formato de campo para registro y cálculo de la incidencia de mildeo polvoso en hojas de mora

\begin{tabular}{|c|c|c|c|c|c|c|c|c|c|c|c|c|c|}
\hline \multirow{2}{*}{ 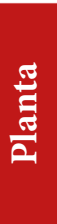 } & \multicolumn{3}{|c|}{ Rama 1} & \multicolumn{3}{|c|}{ Rama 2} & \multicolumn{3}{|c|}{ Rama 3} & \multicolumn{3}{|c|}{ Rama 4} & \multirow{2}{*}{$\begin{array}{c}\text { Incidencia/ } \\
\text { planta } \\
\text { ramas } \\
\text { (promedio } \\
\text { IR \%) }\end{array}$} \\
\hline & HTR & HE & IR \% & HTR & HE & IR $\%$ & HTR & HE & IR \% & HTR & HE & IR \% & \\
\hline 1 & 18 & 6 & 33 & 12 & 4 & 33 & 18 & 6 & 33 & 14 & 6 & 42 & 35 \\
\hline 2 & 22 & 8 & 36 & 10 & 3 & 30 & 13 & 4 & 30 & 19 & 8 & 42 & 34 \\
\hline 3 & 26 & 6 & 23 & 15 & 4 & 26 & 15 & 6 & 40 & 12 & 3 & 25 & 28 \\
\hline 4 & 30 & 7 & 23 & 18 & 6 & 33 & 14 & 3 & 21 & 11 & 4 & 36 & 28 \\
\hline 5 & 14 & 6 & 43 & 22 & 6 & 27 & 16 & 5 & 31 & 13 & 4 & 30 & 32 \\
\hline \multicolumn{13}{|c|}{ Promedio total para el cultivo } & 31 \\
\hline
\end{tabular}

HTR: hojas totales por rama, HE: hojas afectadas, IR: incidencia por rama.

Fuente: Elaboración propia 
Para el ejemplo en estudio, la incidencia promedio de mildeo polvoso en hojas es del $31 \%$ estimado para la plantación. Esta información se debe analizar junto con la valoración de la severidad en hojas y la incidencia en estructuras reproductivas (si están afectadas), para la toma de decisiones de manejo de la enfermedad.

\section{Mildeo polvoso, severidad en hojas}

En las ramas seleccionadas (cuatro ramas jóvenes por planta, orientadas hacia al norte, sur, oriente y occidente), se realiza la cuantificación de la severidad de la enfermedad en seis hojas por rama (iniciando por la hoja más joven que esté completamente abierta), para lo cual se hace uso de los diagramas (figura 7), que se comparan con las hojas afectadas y, por apreciación visual, se reconoce y registra el porcentaje del tejido enfermo observado ( $1 \%, 5 \%, 10 \%, 25 \%, 50 \%)$. Se califica la severidad por hoja y se promedian los valores para obtener la severidad por rama; luego, se halla la severidad promedio por planta y para todo el cultivo.

Por ejemplo, para estimar la severidad por rama, se procede de la siguiente manera: en la rama 1 de la planta 1 en las 6 hojas, los valores encontrados para severidad, con la aplicación de los diagramas (figura 7), fueron los siguientes: hoja 1: $10 \%$; hoja 2: $5 \%$; hoja 3: $5 \%$; hoja 4: $5 \%$, hoja 5: $5 \%$; y hoja 6: $0 \%$. Se promedian estos valores a fin de obtener la severidad para la rama; en este caso, el promedio es del $5 \%$ y se asigna este valor para la rama 1 de la planta 1 (tabla 12). De manera similar, se procede para el resto de las ramas seleccionadas para el monitoreo. En la tabla 12 , se registran los valores promedio encontrados para las ramas a partir de la evaluación de la severidad en las hojas de cada rama.

Tabla 12. Formato de campo para el cálculo de la severidad de mildeo polvoso en ramas de mora

\begin{tabular}{|c|c|c|c|c|c|c|}
\hline Planta & Rama 1 & Rama 2 & \multicolumn{2}{c|}{ Rama 3 } & Rama 4 & $\begin{array}{c}\text { Severidad/ } \\
\text { planta ramas }\end{array}$ \\
\hline \multicolumn{7}{|c|}{} \\
\hline
\end{tabular}


La severidad promedio de mildeo polvoso en ramas (estimado a partir de hojas) para el cultivo es del 9,3\%, calificada como media (entre el 5 y el $20 \%$ ).

\section{Mildeo polvoso, incidencia en estructuras reproductivas (botones florales, flores y frutos)}

En cada uno de los cuatro racimos seleccionados, se cuentan las estructuras totales (botones florales, flores y frutos) y las estructuras afectadas por mildeo polvoso, y se aplica la ecuación 4 .

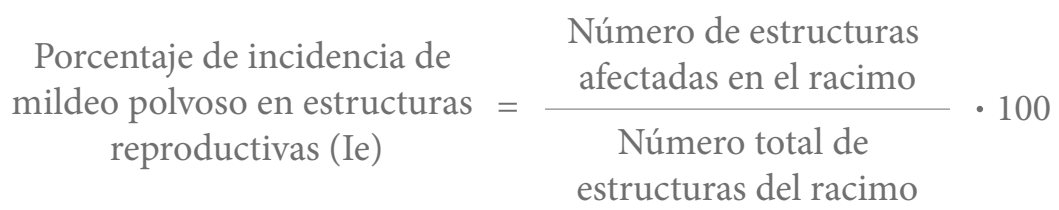

Ecuación 4

El conteo en campo registró los valores presentados en la tabla 13.

Tabla 13. Formato de campo para el cálculo de la incidencia de mildeo polvoso en estructuras reproductivas de mora: botones florales, flores y frutos

\begin{tabular}{|c|c|c|c|c|c|c|c|c|c|c|c|c|c|}
\hline \multirow[b]{2}{*}{ Planta } & \multicolumn{3}{|c|}{ Racimo 1} & \multicolumn{3}{|c|}{ Racimo 2} & \multicolumn{3}{|c|}{ Racimo 3} & \multicolumn{3}{|c|}{ Racimo 4} & \multirow{2}{*}{$\begin{array}{c}\text { Incidencia/ } \\
\text { planta } \\
\text { racimo } \%\end{array}$} \\
\hline & ET & EA & IR \% & ET & EA & IR \% & ET & EA & IR\% & ET & EA & IR\% & \\
\hline 1 & 60 & 20 & 33 & 34 & 12 & 35 & 46 & 23 & 50 & 24 & 11 & 45 & 40 \\
\hline 2 & 54 & 15 & 27 & 43 & 13 & 30 & 45 & 31 & 68 & 18 & 8 & 44 & 42 \\
\hline 3 & 43 & 10 & 23 & 54 & 23 & 42 & 38 & 6 & 15 & 14 & 6 & 42 & 30 \\
\hline 4 & 34 & 13 & 38 & 36 & 10 & 27 & 36 & 11 & 30 & 27 & 10 & 37 & 33 \\
\hline 5 & 45 & 15 & 33 & 42 & 11 & 26 & 44 & 13 & 29 & 17 & 9 & 52 & 35 \\
\hline \multicolumn{13}{|c|}{ Promedio total para el cultivo } & 36 \\
\hline
\end{tabular}

ET: estructuras (botones florales, flores y frutos) totales por racimo, EA: estructuras afectadas, IR: incidencia por racimo.

Fuente: Elaboración propia

Se halla la incidencia por racimo (IR), el promedio por planta y el promedio total para el cultivo. Al calcular la incidencia, esta corresponde al $36 \%$ para la plantación evaluada, calificada como alta (mayor del 29\%). Las incidencias del $36 \%$ en estructuras 
reproductivas y el $31 \%$ en hojas con severidad del 9,3\% requieren acciones urgentes, las que se describen en el apartado "Manejo integrado de mildeo polvoso, cenicilla, crespera".

\section{Moho gris en frutos, incidencia en frutos}

En cada uno de los racimos seleccionados con frutos en grado 4 de maduración o superior (Icontec 1997), se cuentan los frutos totales por racimo (FTR), los frutos enfermos (FE) por moho gris y se calcula la incidencia para cada racimo (IR) según la ecuación 5 .

$\begin{gathered}\text { Porcentaje de incidencia de } \\ \text { moho gris en frutos (If) }\end{gathered}=\frac{\text { Número de frutos afectados en el racimo }}{\text { Número total de frutos del racimo }} \cdot 100$

Ecuación 5

Por ejemplo, en campo se encontraron los siguientes valores de frutos totales y enfermos por moho gris (tabla 14).

Tabla 14. Formato de campo para registro y cálculo de la incidencia de moho gris en frutos de mora

\begin{tabular}{|c|c|c|c|c|c|c|c|c|c|c|c|c|c|}
\hline \multirow[b]{2}{*}{ Planta } & \multicolumn{3}{|c|}{ Racimo 1} & \multicolumn{3}{|c|}{ Racimo 2} & \multicolumn{3}{|c|}{ Racimo 3} & \multicolumn{3}{|c|}{ Racimo 4} & \multirow{2}{*}{$\begin{array}{c}\text { Incidencia/ } \\
\text { planta } \\
\text { racimo } \%\end{array}$} \\
\hline & FTR & FE & IR \% & FRT & FE & IR \% & FTR & FE & IR \% & FTR & FE & IR \% & \\
\hline 1 & 28 & 3 & 10 & 15 & 2 & 13 & 24 & 0 & 0 & 18 & 3 & 16 & 10 \\
\hline 2 & 13 & 0 & 0 & 12 & 1 & 8 & 10 & 1 & 10 & 28 & 2 & 7 & 6 \\
\hline 3 & 23 & 1 & 4 & 21 & 1 & 4 & 8 & 2 & 25 & 32 & 4 & 12 & 11 \\
\hline 4 & 32 & 2 & 6 & 16 & 2 & 12 & 13 & 1 & 7 & 40 & 2 & 5 & 7 \\
\hline 5 & 42 & 3 & 7 & 14 & 0 & 0 & 14 & 2 & 14 & 10 & 0 & 0 & 5 \\
\hline \multicolumn{13}{|c|}{ Promedio total para el cultivo } & 8 \\
\hline
\end{tabular}

ET: estructuras (botones florales, flores y frutos) totales por racimo, EA: estructuras afectadas, IR: incidencia por racimo.

Fuente: Elaboración propia

Se procesa la información para obtener la incidencia de la enfermedad por racimo y luego se halla el promedio por planta y para el cultivo. En el ejemplo, correspondió al $8 \%$, calificada como baja (menor del $25 \%$ ), lo cual indica que se deben mantener las prácticas culturales recomendadas para el manejo de la enfermedad y continuar el monitoreo. 
El resumen del estado fitopatológico del cultivo monitoreado se muestra en la tabla 15.

Tabla 15. Reporte de niveles de incidencia y severidad para cuatro enfermedades en mora

\begin{tabular}{|c|c|c|c|c|c|c|c|c|}
\hline \multicolumn{9}{|c|}{ Enfermedad } \\
\hline \multicolumn{2}{|c|}{$\begin{array}{c}\text { Antracnosis } \\
\%\end{array}$} & \multicolumn{3}{|c|}{$\begin{array}{c}\text { Mildeo velloso } \\
\%\end{array}$} & \multicolumn{3}{|c|}{$\begin{array}{c}\text { Mildeo polvoso } \\
\%\end{array}$} & \multirow{2}{*}{$\begin{array}{c}\text { Moho gris } \\
\%\end{array}$} \\
\hline IT & ST & IT & ST & IF & IH & SH & IER & \\
\hline 59 & 2,4 & 42 & 4,3 & 55,6 & 31 & 9,3 & 36 & 8 \\
\hline
\end{tabular}

IT porcentaje (\%) de incidencia en tallos. ST porcentaje (\%) de severidad en tallos. IF porcentaje (\%) de incidencia en frutos. IH porcentaje (\%) de incidencia en hojas. SH porcentaje (\%) de severidad en hojas. IER porcentaje (\%) de incidencia en estructuras reproductivas. Fuente: Elaboración propia

\section{Interpretación de resultados}

La antracnosis afecta el $59 \%$ de los tallos, con una severidad del 2,4\% calificada como media (entre el $2 \%$ y el $10 \%$ ), lo cual genera alerta si se considera que las lesiones pueden progresar y comprometer áreas mayores en tallos.

En cuanto a mildeo velloso, la situación demanda medidas de choque, en especial por la alta incidencia en frutos (55\%). A pesar de que el $42 \%$ de los tallos presente una severidad del 4,3\% calificada como baja (inferior al $5 \%$ ), se tiene en cuenta la pérdida de frutos y la fuente de inóculo que estos representan. Para complementar el manejo, se puede emplear un fungicida que controle mildeo velloso y antracnosis simultáneamente; puede ser aquellos que contengan ingredientes activos, como azoxystrobin. La rotación de moléculas debe considerar productos con ingrediente activo fosetil aluminio, que, además de ser eficiente para el control del patógeno, estimula la producción de defensas en la planta.

Para el mildeo polvoso, la situación por la que atraviesa el cultivo es crítica, en especial por la afectación de las estructuras reproductivas con una incidencia superior al $29 \%$, donde se presenta pérdida económica. Requiere la aplicación de las recomendaciones descritas en el apartado "Manejo integrado de mildeo polvoso, cenicilla, crespera". El control químico se puede iniciar con fungicidas que contengan el ingrediente activo difenoconazol (que también ayuda al control de antracnosis), en rotación con otro a base de azufre. Si la temporada es seca, hay que prestar especial atención a esta enfermedad. 
Respecto del moho gris, que presentó el $8 \%$ de incidencia, se deben atender las acciones planteadas en la tabla 5 y las recomendaciones para el manejo integrado de la enfermedad. Las podas que se realizan para el control de la antracnosis y los mildeos también ayudan al control de moho gris.

Una vez realizadas las prácticas de manejo, se continúa con el monitoreo de las enfermedades con frecuencia semanal o quincenal (siempre en estructuras diferentes de las que se hallan leído en el monitoreo anterior), según las condiciones climatológicas y la susceptibilidad del genotipo de mora, con el fin de tomar las decisiones que garanticen el mantenimiento de buenas condiciones fitosanitarias y de producciones elevadas.

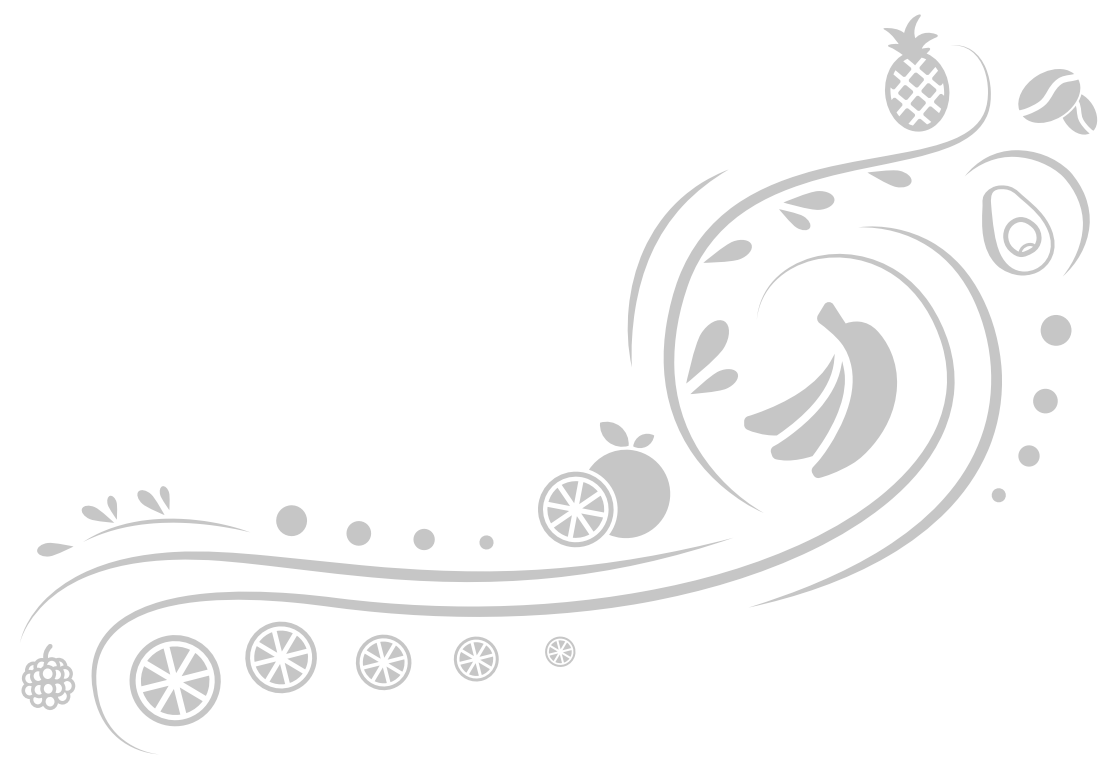




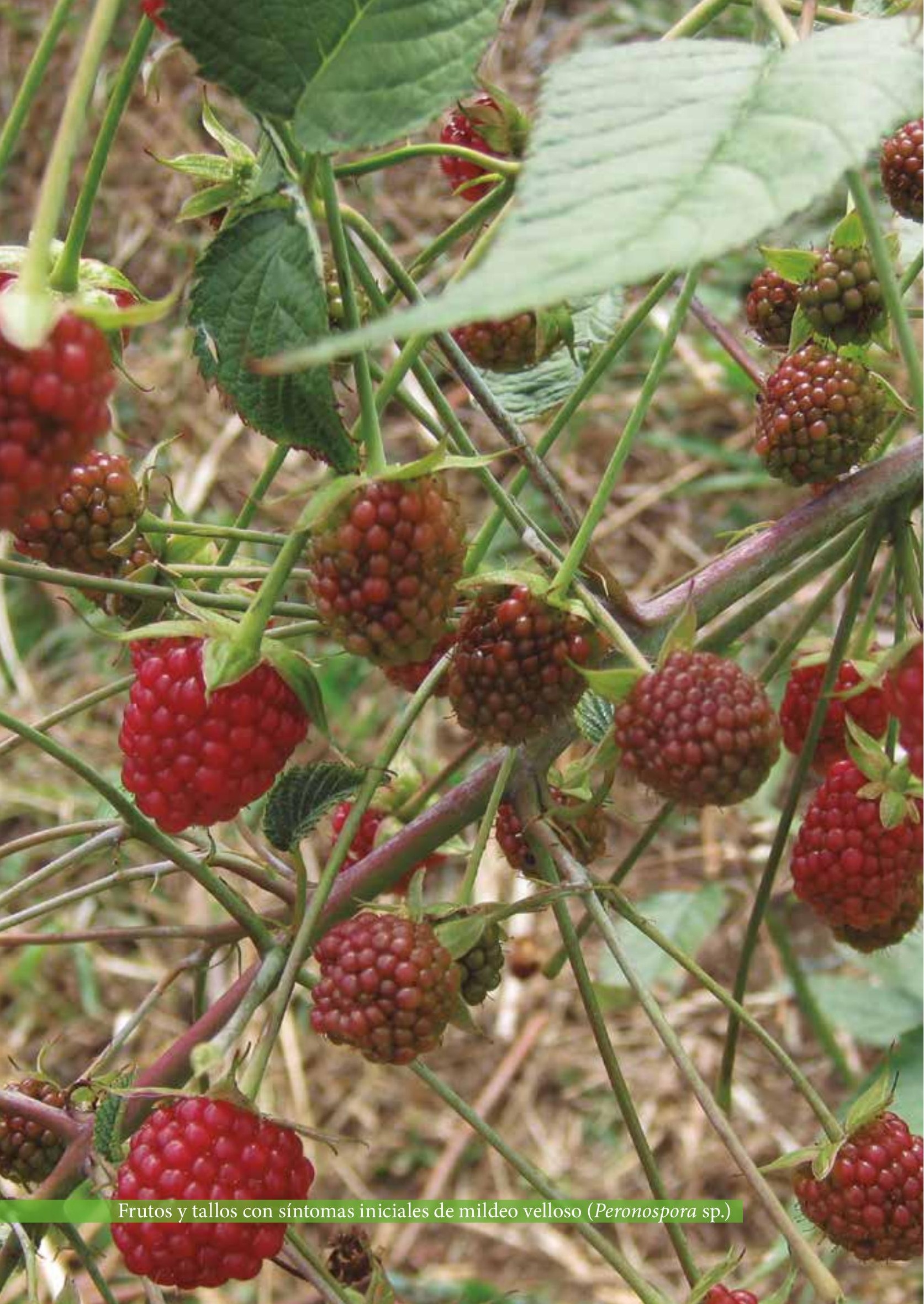




\section{Los autores}

\section{Alegría Saldarriaga Cardona \\ asaldarriaga@corpoica.org.co}

Ingeniera agrónoma de la Universidad Nacional de Colombia, sede Medellín, MSc en Fitopatología de la Universidad de Caldas (Colombia). En la actualidad, se desempeña como investigadora MSc en enfermedades de frutales y hortalizas de clima frío moderado y musáceas, en el Centro de Investigación La Selva de la Corporación Colombiana de Investigación Agropecuaria (Corpoica).

\section{Germán Franco}

gfranco@corpoica.org.co

Ingeniero agrónomo de la Universidad de Caldas, $\mathrm{PhD}$ en Ciencias Agrarias de la Universidad Nacional de Colombia, sede Medellín (Colombia). En la actualidad, se desempeña como investigador $\mathrm{PhD}$ asociado en fisiología de poscosecha en el Centro de Investigación La Selva de la Corporación Colombiana de Investigación Agropecuaria (Corpoica).

\section{Cipriano Arturo Díaz Diez}

cdiaz@corpoica.org.co

Ingeniero agrónomo y MSc en Ciencias Agrarias de la Universidad Nacional de Colombia, sede Medellín (Colombia). En la actualidad, se desempeña como investigador MSc sénior en fisiología de cultivos en el Centro de Investigación La Selva de la Corporación Colombiana de Investigación Agropecuaria (Corpoica).

\section{Gladis Emilia Múnera Uribe}

gmunera@corpoica.org.co

Ingeniera agrónoma de la Universidad Nacional de Colombia, sede Medellín, MSc of Science in Nematology y Doctor of Science: Biology de Ghent University (Bélgica). En la actualidad, se desempeña como investigador $\mathrm{PhD}$ en manejo integrado de sistemas productivos en el Centro de Investigación La Selva de la Corporación Colombiana de Investigación Agropecuaria (Corpoica). 


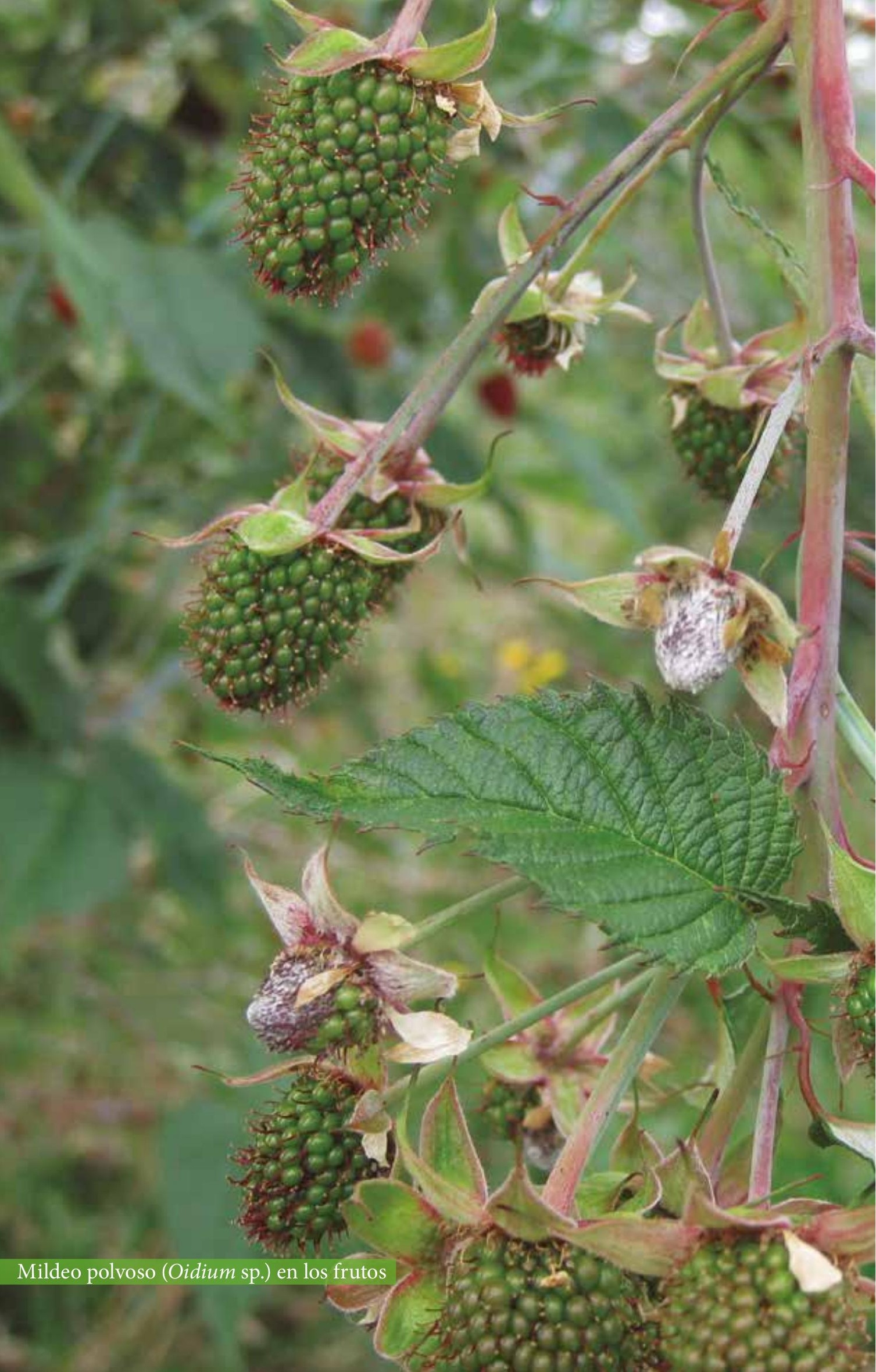




\section{Referencias}

Afanador L, Álvarez E, González A, Mejía J. 2009. Especies de Colletotrichum causantes de la antracnosis de mora de Castilla (Rubus glaucus Benth.) en Colombia. En: [Ascolfi] Asociación Colombiana de Fitopatología y Ciencias Fines. Memorias del xxix Congreso Internacional de Fitopatología y Ciencias Afines: Patología vegetal, pasado, presente y futuro. Medellín, Colombia: Ascolfi. pp. 107-108.

Arroyave G, Salazar M. s. f. Guía técnica del cultivo de mora. Manizales: Litomaster. Ávila W, González R, Forero MC, Vargas A. 2003. Penetración, infección y sitios de ataque del hongo Colletotrichum gloeosporioides en plantas de mora de Castilla. En: [Ascolfi] Asociación Colombiana de Fitopatología y Ciencias Fines. Memorias del xxiv Congreso Nacional de Fitopatología. Armenia, Colombia: Ascolfi. p. 4-5.

Betancourt M, Palacios S, Patiño AA. 2014. Fichas técnicas para la identificación y manejo de enfermedades y plagas en mora. Santa Rosa de Cabal, Colombia: [Unisarc] Corporación Universitaria Santa Rosa de Cabal.

Botero MJ, Franco G, Castaño J, Ramírez MC. 1999. Principales enfermedades en poscosecha asociadas a cultivos de lulo, manzano, mora y tomate de árbol. Manizales, Colombia: Universidad de Caldas, [Corpoica] Corporación Colombiana de Investigación Agropecuaria, [sEnA] Servicio Nacional de Aprendizaje.

Botero MJ, Ríos G, Franco G, Romero M, Pérez JC, Morales JE, Gallego JL y Echeverri DI. 2002. Identificación y espacialización de enfermedades asociadas a los cultivos de mora (Rubus glaucus Benth.) en el eje cafetero. En: [Corpoica] Corporación Colombiana de Investigación Agropecuaria, [UPB] Universidad Pontificia Bolivariana, [CDTF] Centro de Desarrollo Tecnológico de Frutales. Memorias del Iv Seminario Frutales de Clima Frío Moderado. Medellín, Colombia: Corpoica, CDTF, UPB. pp. 87-92.

Botero MJ, Castellanos PA, Zuluaga LE. 2003. Identificación de enfermedades asociadas al cultivo de mora (Rubus glaucus Benth.), en un sistema agroforestal en el municipio de Santa Rosa de Cabal (Risaralda). En: Castellanos PA, Botero RG, editores. Evaluación de especies forestales con potencial de tutores vivos en la producción de mora (Rubus glaucus Benth.). Boletín de Investigación. Manizales, Colombia: [Corpoica] Corporación de Investigación Agropecuaria, [Pronatta] Programa de Transferencia de Tecnología Agropecuaria. pp. 25-30. 
Botero MJ, Franco G. 2007. Identificación y caracterización preliminar del agente causal de la mancha necrótica de las hojas de la mora (Rubus glaucus) en el municipio de Trujillo (Valle del Cauca, Colombia). Corpoica Cienc Tecnol Agropecuaria. 8(2):22-25.

Buriticá P. 1999. Directorio: patógenos y enfermedades de las plantas de importancia económica en Colombia. Bogotá: [ICA] Instituto Colombiano Agropecuario.

Castaño J. 1994. Principios básicos de fitopatología. 2a ed. Zamorano, Honduras: Zamorano AcademicPress.

Castaño J. 2002. Principios básicos de fitoepidemiología. Manizales, Colombia: Universidad de Caldas.

Castaño J. 2015. Principios básicos de hongos fitopatógenos. Manizales, Colombia: Universidad de Caldas.

Castellanos PA, Botero RG. 2003. Producción de mora (Rubus glaucus Benth.) con tutores vivos. Manizales, Colombia: [Corpoica] Corporación Colombiana de Investigación Agropecuaria.

Castro D, Díaz JJ. 2001. Alternativas para el manejo integrado del cultivo de la mora (Rubus glaucus Benth.). Rionegro, Colombia: Universidad Católica de Oriente, [Pronatta] Programa Nacional de Transferencia de Tecnología Agropecuaria.

Díaz C, Saldarriaga A, Navas G, Tamayo A, Zapata JL. 2009. Tecnologías que contribuyan a la implementación de las BPA en el cultivo de la mora (Rubus glaucus Benth.) en Antioquia y Caldas. Informe final de proyecto. Rionegro, Colombia: [Corpoica] Corporación Colombiana de Investigación Agropecuaria.

Díaz C, Medina C, Saldarriaga A, Tamayo P, Franco G, Passaro C, Munera G, Guarín J, Córdoba O, Ríos G, et al. 2013. Diez (10) genotipos de mora identificados por calidad (grados brix, acidez, tamaño de fruto y rendimiento). Bogotá: [Corpoica] Corporación Colombiana de Investigación Agropecuaria-Centro de Investigación La Selva, Ministerio de Agricultura y Desarrollo Rural.

Forero MC, Ávila W, González R. 2002. Estudio sobre antracnosis en mora de Castilla. En: [Corpoica] Corporación Colombiana de Investigación Agropecuaria, [UPB] Universidad Pontificia Bolivariana, [CDTF] Centro de Desarrollo Tecnológico de Frutales. Memorias de Iv Seminario Frutales de Clima Frío Moderado. Medellín: Corpoica, CDTF, UPB. pp. 220-228.

Forero MC. 2007. Uchuva (Physalis peruviana L.) y mora de Castilla (Rubus glaucus Benth.): enfermedades y manejo. En: [Ascolfi] Asociación Colombiana de Fitopatología y Ciencias Fines. Memorias del xxviII Congreso Asociación Colombiana de Fitopatología y Ciencias Afines. Palmira, Colombia: Ascolfi. pp. 1-7. 
Franco G, Giraldo M. 2002. El cultivo de la mora. Manizales, Colombia: [Corpoica] Corporación Colombiana de Investigación Agropecuaria.

Gaviria V. 2011. Evaluación in vitro de diferentes fungicidas comerciales de origen vegetal, origen biológico y de síntesis química para el control de Colletotrichum gloeosporioides y Colletotrichum acutatum en la mora de Castilla Rubus glaucus Benth. [trabajo de grado]. [Medellín, Colombia]: Politécnico Colombiano Jaime Isaza Cadavid.

González R, Ávila W, Forero MC, Vargas A. 2003. Estudios sobre la severidad y avance del hongo Colletotrichum gloeosporioides agente causante de la antracnosis en mora de Castilla. En: [Ascolfi] Asociación Colombiana de Fitopatología y Ciencias Fines. Memorias del xxiv Congreso Nacional de Fitopatología. Armenia, Colombia: Ascolfi.

Hincapié O. 2010. Evaluación de alternativas para el manejo integrado de enfermedades en el cultivo de mora (Rubus glaucus Benth.) en Rionegro, Antioquia [tesis de grado]. [Medellín, Colombia]: Politécnico Colombiano Jaime Isaza Cadavid. Hincapié O, Saldarriaga A. 2009. Avances de investigación en la exploración de alternativas para el manejo integrado de las principales enfermedades de la mora. En: [Corpoica] Corporación Colombiana de Investigación Agropecuaria. Memorias del Seminario de Actualización Tecnológica: Cultivo, agroindustria y comercialización de la mora de Castilla [CD]. Rionegro, Antioquia: Corpoica. Hincapié O, Saldarriaga A, Díaz C. 2010. Avances sobre alternativas para el manejo integrado del moho gris (Botrytis cinerea Pers. Ex Fr.) en el cultivo de la mora (Rubus glaucus Benth.). En: [Corpoica] Corporación Colombiana de Investigación Agropecuaria, [UPB] Universidad Pontificia Bolivariana, [CDTF] Centro de Desarrollo Tecnológico de Frutales. Memorias del vir Seminario Internacional de Frutas Tropicales: Agroindustria e innovación. Medellín: Corpoica, UPB, CDTF. pp. 94.

[Icontec] Instituto Colombiano de Normas Técnicas y Certificación. 1997. Norma Técnica Colombiana NTC-4106. Frutas Frescas. Mora de Castilla. Especificaciones. Bogotá, Colombia: Icontec.

Marulanda ML, López AM, López JM, Isaza L, Gómez LM, Arias J. 2011. Resultados de investigaciones en mora de Castilla: una aplicación para el agricultor (2008-2011). Pereira, Colombia: [utp] Universidad Tecnológica de Pereira.

Mesa NC, Gómez ED, Mena YM, Londoño LA, Imbachi K, Romero R Salazar JA, Hernández CA, Huertas CA, Vásquez D, et al. 2014. Programa de manejo fitosanitario en mora en el departamento del Valle del Cauca. Palmira, Colombia: Universidad Nacional de Colombia. 
Múnera G, Navas G, Díaz C, Saldarriaga A, Zapata J, Tamayo P, Guarín J, Macías A, Hincapié M, González A, et al. 2012. Actualización y transferencia sobre el manejo integrado de los cultivos de lulo, uchuva y mora con énfasis en el componente fitosanitario, para los productores y asistentes técnicos de Antioquia y eje cafetero. Informe final de proyecto. Rionegro, Colombia: [Corpoica] Corporación Colombiana de Investigación Agropecuaria-Centro de Investigación La Selva.

Peláez A, Castro D, Tamayo PJ. 2000. Control integrado de Peronospora y Botrytis cinerea en frutos de mora de Castilla (Rubus glaucus Benth.). En: Memorias del III Seminario de Frutales de Clima Frío Moderado. Manizales; Colombia: [Corpoica] Corporación Colombiana de Investigación Agropecuaria. pp. 166-172.

Pérez L. 1994. Patología vegetal. Bogotá, Colombia: Produmedios.

PLM. 2016. Diccionario de especialidades agroquímicas. Bogotá, Colombia: PLM.

Rodríguez JL, Franco G, Rodríguez A, Santana G, Bernal J. 2000. Aspectos socioeconómicos del cultivo de la mora (Rubus glaucus Benth.) en Colombia y el eje cafetero central. En: [Corpoica] Corporación Colombiana de Investigación Agropecuaria, [UPB] Universidad Pontificia Bolivariana, [CDTF] Centro de Desarrollo Tecnológico de Frutales. Memorias del III Seminario de Frutales de Clima Frío Moderado. Manizales, Colombia: Corpoica, UPB, CDTF. pp. 298-304.

Rueda K. 2010. Caracterización molecular de especies de Colletotrichum prevalentes en las zonas productoras de mora de Castilla (Rubus glaucus Benth.) en Antioquia [tesis de maestría]. [Medellín, Colombia]: Universidad Nacional de Colombia.

Rueda KR, Saldarriaga A, Cadavid GE, Saldamando CI, Cañas GP, Arango RE. 2012. Differential organ distribution, pathogenicity and benomyl sensitivity of Colletotrichum spp. from blackberry plants in northern Colombia. J Phytopathol. [consultado 2012 dic 12];161(4):246-253. http://onlinelibrary.wiley.com doi/10.1111/ jph.12040/full. doi: 10.1111/jph.12040.

Saldarriaga A. 2006. Caracterización del agente causante de la antracnosis en tomate de árbol, manzana y mora [tesis de maestría]. [Manizales, Colombia]: Universidad de Caldas.

Saldarriaga A. 2012. Anexo 14. Informe enfermedades. En: Múnera G, Navas G, Díaz C, Saldarriaga A, Zapata J, Tamayo P, Guarín J, Macías A, Hincapié M, González A, et al. Actualización y transferencia sobre el manejo integrado de los cultivos de lulo, uchuva y mora con énfasis en el componente fitosanitario, para los productores y asistentes técnicos de Antioquia y eje cafetero. Informe final de proyecto. Rionegro, Colombia: [Corpoica] Corporación Colombiana de Investigación Agropecuaria, Centro de Investigación La Selva. 
Saldarriaga A, Bernal J. 2000. Enfermedades asociadas a los cultivos de mora (Rubus glaucus Benth.) en el departamento de Antioquia. En: [Corpoica] Corporación Colombiana de Investigación Agropecuaria, [UPB] Universidad Pontificia Bolivariana, [CDTF] Centro de Desarrollo Tecnológico de Frutales. Memorias del III Seminario de Frutales de Clima Frío Moderado. Manizales, Colombia: Corpoica, UPB, CDTF. pp. 132-135.

Saldarriaga A, Rodríguez E, Arango R. 2002. Estudios biológicos de aislamientos de Colletotrichum sp., a partir de frutos de tomate de árbol, manzano y tallos de mora. En: [CIB] Corporación para Investigaciones Biológicas. Memorias del viII Congreso Corporación para Investigaciones Biológicas. Medellín, Colombia: CIв. pp. 21.

Saldarriaga A, Navas G, Franco G, Ríos G, Vásquez L, Navas A, Gonzáles S, Gaviria V, Macías A, Gómez E, et al. 2012. Biología, caracterización y comportamiento del patógeno de la antracnosis de la mora como base para establecer estrategias de manejo. Informe final de proyecto. Rionegro, Colombia: [Corpoica] Corporación Colombiana de Investigación Agropecuaria, Centro de Investigación La Selva.

Saldarriaga-Cardona A, Castaño-Zapata J, Arango-Isaza R. 2008. Caracterización del agente causal de la antracnosis en tomate de árbol, manzano y mora. Rev Acad Colomb Cienc. 32(123):145-156.

Tamayo PJ. 2003. Principales enfermedades del tomate de árbol, la mora y el lulo en Colombia. Boletín Técnico. 20:16-25.

Tamayo PJ. 2009. Enfermedades. En: [Corpoica] Corporación Colombiana de Investigación Agropecuaria. Memorias del Seminario de Actualización Tecnológica: Cultivo, agroindustria y comercialización de la mora de Castilla [CD]. Rionegro, Colombia: Corpoica, Centro de Investigación La Selva.

Tamayo P, Peláez A. 2000. Caracterización de daños y pérdidas causadas por enfermedades del fruto de la mora de Castilla (Rubus glaucus Benth.) en Antioquia. En: [Corpoica] Corporación Colombiana de Investigación Agropecuaria, [upB] Universidad Pontificia Bolivariana, [CDTF] Centro de Desarrollo Tecnológico de Frutales. Memorias del III Seminario de Frutales de Clima Frío Moderado. Manizales, Colombia:Corpoica, UPB, CDTF.pp. 174-179.

Zapata JA, Cotes AM, Uribe LA, Díaz A, Villamizar LF, Gómez MI, Saldarriaga A, Álvarez R, Gómez E. 2013. Desarrollo de prototipos de bioplaguicidas a base de Rhodotorula glutinis LvCo7 para el control de Botrytis cinerea en cultivos de mora. Bogotá, Colombia: [Corpoica] Corporación Colombiana de Investigación Agropecuaria. 
Impresión y encuadernación:

Fundación Cultural Javeriana de Artes Gráficas (Javegraf)

Terminó de imprimirse en agosto de 2017, Bogotá, D. C., Colombia 
Las enfermedades de la mora de Castilla (Rubus glaucus Benth.), son un factor limitante de la producción por los daños directos que ocasionan en las plantas, puesto que afectan los rendimientos, la calidad del producto, la vida útil del cultivo y los ingresos del productor, debido al costo económico que representa el manejo. Lo expuesto dificulta la obtención de fruta con el estándar de calidad requerido por la industria y el mercado en fresco, por lo que se pierden oportunidades de negocio. En consecuencia, el conocimiento del estado fitosanitario del cultivo es fundamental para la definición de las estrategias de manejo a implementar en la plantación. Las nuevas realidades del mercado orientan hacia la necesidad de una producción más eficiente y sostenible, con un uso racional de los plaguicidas, para obtener fruta que cumpla con los requisitos de calidad e inocuidad, además de contribuir a la conservación del ambiente y la salud de los productores. El objetivo de este manual es brindar orientación para el diagnóstico y la cuantificación de las enfermedades, mediante el uso de metodologías e ilustraciones, que permiten estimar el estado fitosanitario de la plantación y las posibles pérdidas económicas en la producción, en un momento dado del cultivo. El documento se fundamenta en resultados de investigación, obtenidos en el desarrollo de proyectos adelantados por Corpoica y otras instituciones, además de experiencias de productores y profesionales con trayectoria en el cultivo. Este manual, presenta descripciones e ilustraciones de las principales enfermedades que afectan este frutal, con guías para su diagnóstico, cuantificación, valoración de pérdidas y su impacto económico y brinda recomendaciones técnicas para el manejo integrado de este sistema productivo.

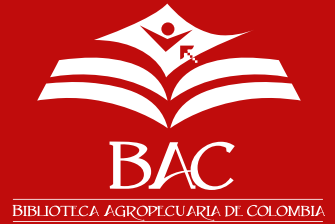

CORREO: bac@corpoica.org.co

TELÉFONO: (57 1) 4227300 EXT. 1257 • 1274

SKYPE: biblioteca.agropecuaria www.corpoica.org.co

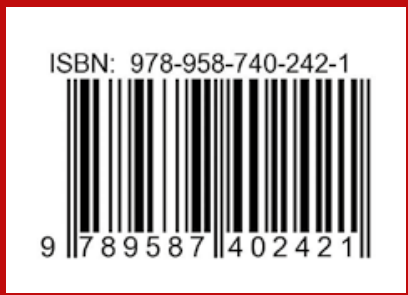

\section{Distribución gratuita Prohibida su venta}

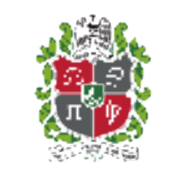

UNIVLRSIDAD

NACIONAL

Dr LOIOMBIA.

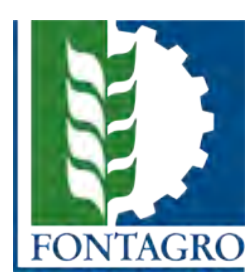

MINAGRICULTURA
TODOS POR UN NUEVO PAÍS 